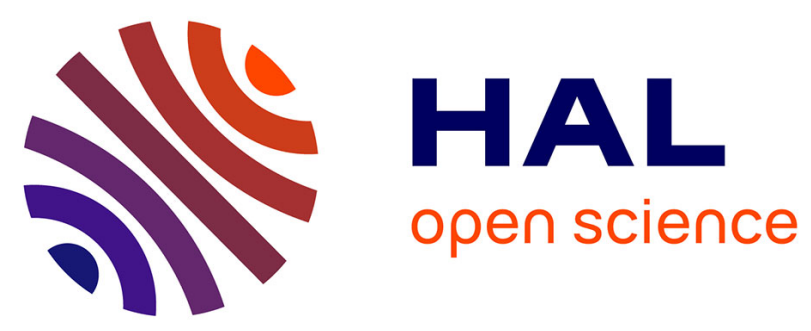

\title{
Upper mantle anisotropy beneath Australia and Tahiti from $P$ wave polarization: Implications for real-time earthquake location
}

Fabrice R. R. Fontaine, Guilhem Barruol, Brian L N Kennett, Goetz H R Bokelmann, Dominique R Reymond

\section{To cite this version:}

Fabrice R. R. Fontaine, Guilhem Barruol, Brian L N Kennett, Goetz H R Bokelmann, Dominique R Reymond. Upper mantle anisotropy beneath Australia and Tahiti from P wave polarization: Implications for real-time earthquake location. Journal of Geophysical Research: Solid Earth, 2009, 114 (B3), pp.B03306. 10.1029/2008JB005709 . hal-01389113

\section{HAL Id: hal-01389113 \\ https://hal.univ-reunion.fr/hal-01389113}

Submitted on 28 Oct 2016

HAL is a multi-disciplinary open access archive for the deposit and dissemination of scientific research documents, whether they are published or not. The documents may come from teaching and research institutions in France or abroad, or from public or private research centers.
L'archive ouverte pluridisciplinaire HAL, est destinée au dépôt et à la diffusion de documents scientifiques de niveau recherche, publiés ou non, émanant des établissements d'enseignement et de recherche français ou étrangers, des laboratoires publics ou privés. 


\title{
Upper mantle anisotropy beneath Australia and Tahiti from $P$ wave polarization: Implications for real-time earthquake location
}

\author{
Fabrice R. Fontaine, ${ }^{1,2}$ Guilhem Barruol, ${ }^{3}$ Brian L. N. Kennett, ${ }^{1}$ Goetz H. R. Bokelmann, ${ }^{3}$
} and Dominique Reymond ${ }^{4}$

Received 19 March 2008; revised 6 November 2008; accepted 31 December 2008; published 20 March 2009.

[1] We report measurements of long-period $P$ wave polarization $\left(P_{\mathrm{pol}}\right)$ in Australia and Tahiti made by combining modeling of the polarization deviation and harmonic analysis. The analysis of the deviation of the horizontal polarization of the $P$ wave as a function of event back azimuth may be used to obtain information about (1) sensor misorientation, (2) dipping discontinuities, (3) seismic anisotropy, and (4) velocity heterogeneities beneath a seismic station. The results from harmonic analysis and a grid search using Snell's law suggest the presence of a dipping seismic discontinuity beneath stations CTAO and CAN in Australia. These results are consistent with published receiver function studies for these stations. The $P_{\text {pol }}$ fast axis orientation is close to the $\mathrm{N}-\mathrm{S}$ absolute plate motion direction at station TAU (Tasmania), which may be due to plate-motion-driven alignment of olivine crystals in the asthenosphere. Interestingly, measurements of $S K S$ splitting at Tahiti (French Polynesia) show an apparent isotropy, whereas an inversion of $P_{\text {pol }}$ observations at PPTL seismic station located in Tahiti suggests the presence of two anisotropic layers. The fast axis azimuth is oriented $\mathrm{E}-\mathrm{W}$ in the upper layer, and it is close to the NW-SE orientation in the lower layer. Since $P_{\text {pol }}$ orientations are used for real-time earthquake locations, especially in poorly instrumented areas such as the South Pacific, we show that the bias from anisotropy and sensor misorientation determined here can be corrected to improve the location accuracy, which yields fundamental data for rapid location necessary for effective tsunami warning.

Citation: Fontaine, F. R., G. Barruol, B. L. N. Kennett, G. H. R. Bokelmann, and D. Reymond (2009), Upper mantle anisotropy beneath Australia and Tahiti from $P$ wave polarization: Implications for real-time earthquake location, J. Geophys. Res., 114, B03306, doi:10.1029/2008JB005709.

\section{Introduction}

[2] In an isotropic medium, the particle motion of $P$ waves (hereafter $P$ polarization, abbreviated $P_{\mathrm{pol}}$ ) is parallel to the ray which is the direction of energy propagation. In an isotropic Earth characterized by a purely depth-dependent velocity, the polarization of $P$ waves and also of Rayleigh waves is parallel to the great circle connecting source (earthquake) and receiver (seismic station), i.e., the radial direction. Observed deviations of polarization from the great circle may have various origins: they may be due to (1) instrument misorientation, or to measurement error [Schulte-Pelkum et al., 2001], (2) lateral velocity variations, (3) dipping interfaces beneath the receiver such as a dipping

\footnotetext{
${ }^{1}$ Research School of Earth Sciences, Australian National University, Canberra, ACT, Australia.

${ }^{2}$ Now at Laboratoire GéoSciences Réunion, UR, IPGP, UMR 7154, Saint Denis, Reunion Island, France.

${ }^{3}$ Laboratoire Géosciences Montpellier, Université Montpellier II, CNRS, Montpellier, France.

${ }^{4}$ CEA, DASE, Laboratoire de Géophysique, Commissariat à l'Energie Atomique, Papeete, Tahiti, French Polynesia.

Copyright 2009 by the American Geophysical Union. 0148-0227/09/2008JB005709\$09.00
}

Mohorovičić discontinuity [Niazi, 1966], and (4) seismic anisotropy [Crampin et al., 1982]. Systematic analysis of this deviation as a function of event back azimuth (station to event) may help distinguish between these different effects and especially to differentiate lateral heterogeneity from seismic anisotropy. Seismic anisotropy is frequently studied using the splitting of teleseismic shear waves such as SKS waves [e.g., Vinnik et al., 1984; Silver and Chan, 1988; Silver and Chan, 1991; Vinnik et al., 1992]. This technique is intrinsically limited by several factors: (1) To record individual $S K S$ phases, events have to occur at epicentral distances larger than $85^{\circ}$ and $S K S$ waves, therefore, sample the upper mantle anisotropy beneath the station at almost vertical incidence. (2) The splitting of the shear waves is integrated along the path and the technique has a poor vertical resolution. (3) The back azimuthal coverage is generally rather poor, preventing multiple-layer analyses to be conducted. The analysis of $P$ wave polarization may therefore be regarded as a complementary technique to investigate upper mantle anisotropy. Being able to use events occurring at epicentral distance ranging from 10 to $70^{\circ}$ has multiple advantages:

[3] 1. The azimuthal coverage is notably increased.

[4] 2. The $P$ waves sample upper mantle anisotropy beneath the station with some lateral offset since their incidence 
angles are much larger (between $17^{\circ}$ and $39^{\circ}$ ) than for $S K S$ phases (incidence angle generally smaller than $10^{\circ}$ ).

[5] 3. $P_{\mathrm{pol}}$ has the ability to vertically locate the anisotropy. The $P$ wave polarization is a local attribute of the ray and thus does not integrate signal along the path. Instead, what is recorded at the Earth's surface will reflect the structure encountered during the last period of propagation of the wave. Using anisotropic reflectivity modeling SchultePelkum et al. [2001] have shown that $P$ particle motion is sensitive to anisotropy only within a wavelength of the seismometer. $P_{\text {pol }}$ should be therefore sensitive to surficial structures (upper crust) at high frequency (i.e., $1 \mathrm{~Hz}$ ) and to lithospheric and asthenospheric structures at longer periods (up to $30 \mathrm{~s}$ ).

[6] Possible causes of deviations from radial polarization are the following:

[7] 1. For sensor misorientation, if the horizontal components are not correctly aligned with the geographic north and east, there will be a constant offset between the polarization and the great circle azimuth, independent of back azimuth and frequency; in this case, one should not expect any back azimuthal periodicity in the $P$ wave polarization.

[8] 2. For seismic anisotropy, upper mantle anisotropy is commonly interpreted as a result of intrinsic elastic anisotropy of rock-forming minerals particularly olivine (which have orthorhombic symmetry) in the upper mantle and from their preferred orientation, developed in response to tectonic forcing [Nicolas and Christensen, 1987; Mainprice et al., 2000]. In the case of seismic anisotropy with a horizontal hexagonal symmetry axis, the horizontal deviation of polarization from the great circle is dependent on the ray azimuth $(\Phi)$. For $P$ waves propagating in a weakly anisotropic material the particle motion can be described to first order as $C_{1} \sin 2 \Phi$, where $C_{1}$ is a function of the ray azimuth and of elastic constants [Davis, 2003]. This $2 \Phi$ dependence corresponds to a $180^{\circ}$ periodicity. Davis [2003] has shown that in the case of orthorhombic symmetry the deviation of $P$ wave horizontal polarization has little dependence on the incidence angle. This holds also for the case of dipping symmetry axes, which, however, induce a $\Phi$ dependence with a $360^{\circ}$ periodicity. As pointed out by various authors [e.g., Schulte-Pelkum et al., 2001; Bokelmann, 2002], travel time delays also depend on terms with $180^{\circ}$ and $360^{\circ}$ periodicity. Petrophysics modeling of $P$ wave polarization in minerals and rocks [Schulte-Pelkum and Blackman, 2003] show a distinct $180^{\circ}$ azimuthal periodicity. This dependence could result from both olivine crystal alignments in the mantle and micro cracks in the crust [Shearer and Chapman, 1989; Bokelmann, 1995].

[9] 3. The presence of small-scale velocity anomalies close to the receiver can result in large polarization anomalies that should not result in an apparent periodicity in the polarization but instead in anomalies visible for particular ranges of azimuths [Girardin and Farra, 1998].

[10] 4. Dipping interfaces in the crust and/or upper mantle should result in a horizontal deviation with periodicity of $360^{\circ}$ [Niazi, 1966].

[11] In this paper, we present a new $P_{\text {pol }}$ method applied on Australian and French Polynesian stations. We benchmark this new technique in Australia which is well studied using other seismic studies. Our aim is to investigate the Australian upper mantle structure and anisotropy in a way complemen- tary to SKS splitting [e.g., Heintz and Kennett, 2006] or surface waves [e.g., Debayle et al., 2005]. We also test this method on a Polynesian station installed in Tahiti where there is no apparent anisotropy from SKS splitting studies [Fontaine et al., 2007]. Upper mantle anisotropy has been indeed recently investigated beneath French Polynesia by the PLUME experiment [Barruol et al., 2002] by analyzing surface waves [Maggi et al., 2006] and SKS splitting [Fontaine et al., 2007]. Anisotropy has been detected by shear wave splitting beneath most sites except Tahiti station PPTL, suggesting the presence of a particular structure in the upper mantle beneath this island, likely induced by the presence of the neighboring Society hot spot, that could be constrained by a complementary technique. Analyzing the influence of sensor misorientation, dipping seismic discontinuity and upper mantle anisotropy on $P$ wave polarization is also of importance for tsunami warning systems such as the Centre Polynésien de Prévention des Tsunamis (CPPT) in French Polynesia, which operates by automatic detection, location and quantification of the magnitude of large earthquakes using both $P$ wave polarization direction and the time difference between $P$ and $S$ waves. We will show that $P_{\text {pol }}$ method could be combined with other seismic studies such as $S K S$ splitting studies to obtain better constrain of the structure beneath a seismic station. We will also show the significance of using this new technique to improve the accuracy of automatic location performed by tsunami warning system with only one seismic station.

\section{Data Analysis}

[12] Our seismic data set is obtained from the permanently installed broadband seismometers in Australia (MBWA, WRAB, CTAO, NWAO, CAN, and TAU) and from two permanent stations installed in Tahiti (French Polynesia) in the same seismic vault (The Geoscope/CEA broadband station PPT and the LDG/CEA long-period station PPTL). All sensors have a flat instrumental response for horizontal and vertical components in the frequency range we are realizing $P_{\mathrm{pol}}$ measurements. We also included data on $P_{\mathrm{pol}}$ observations at Tahiti from E. Gaucher (unpublished data, 1994) which evidenced clear deviations of the $P$ wave polarization for some back azimuths.

[13] We used $P$ waves from epicentral distances between $10^{\circ}$ and $70^{\circ}$, hand-selected good signal-to-noise ratio (i.e., SNR $>2$ ) events, and avoided interference from other phases. The seismograms were rotated into the receiver-to-source azimuth and band-pass filtered in the period range 14-33 s. We used this period range to stay close to the long-period noise notch: a minimum noise level observed at our seismic stations which is present worldwide in the range $20-30 \mathrm{~s}$ [Webb, 1998]. With these signal periods, $P_{\mathrm{pol}}$ should be sensitive to seismic anisotropy down to depths in the range of 60 to $270 \mathrm{~km}$ beneath the receiver [Schulte-Pelkum et al., 2001]. Such a period range therefore has the advantage that it samples pervasive deformation in the upper mantle at the scale of the lithosphere and the asthenosphere. We performed measurements of $P$ wave polarization in a $40 \mathrm{~s}$ window around the onset of the $P$ phase. The technique uses a principal component analysis [Pearson, 1901; Hotelling, 1933] to estimate two angles from the particle motion: (1) the horizontal polarization relative to the radial direction (change 

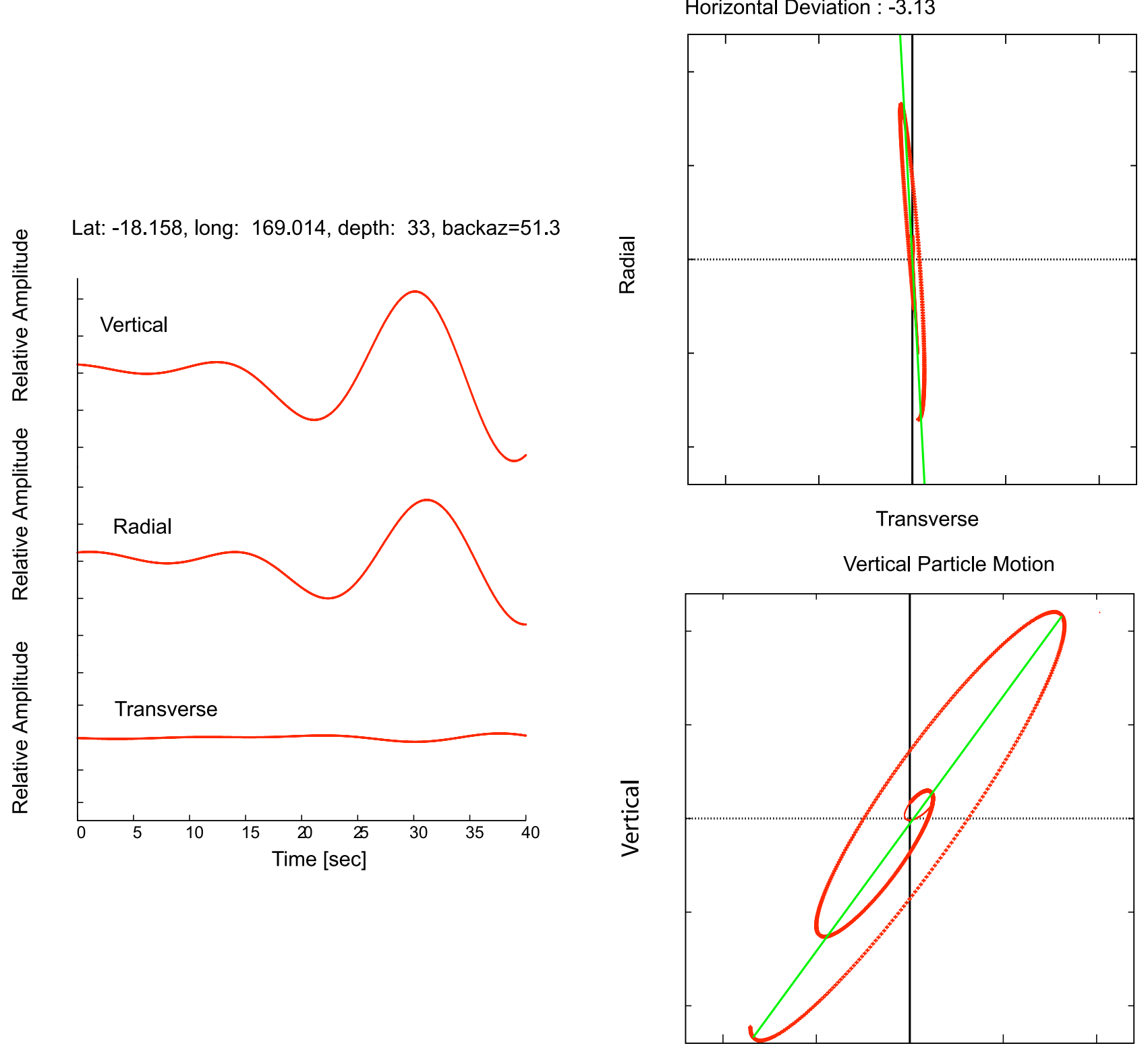

Radial

Figure 1. Example of $P_{\mathrm{pol}}$ measurement obtained at CAN for an earthquake occurring in the Vanuatu region; year 2000 , day 060 , at latitude $18.158^{\circ} \mathrm{S}$, longitude $169.014^{\circ}$, depth $33 \mathrm{~km}$. The epicentral distance is $24.7^{\circ}$ and the back azimuth $51.3^{\circ}$. The departure of the actual polarization of the $P$ wave in the horizontal plane from the radial direction (horizontal deviation of polarization: $-3.13^{\circ}$ ) is illustrated.

in polarization, $\delta \theta$ ) and (2) the vertical polarization. The covariance matrix is formed from a principal component analysis [e.g., Barruol et al., 2006] applied to the three component records. The covariance matrix is equal to $\left(1 / N_{p}\right)$ $\left(Y^{\prime} \cdot Y\right)$, where $N_{p}$ is the number of points in the time window, $Y$ is a $\left(N_{p}^{*} 3\right)$ centered matrix with the components (east, north, vertical up) as its columns, and $Y^{\prime}$ is the transpose of $Y$. $Y$ is mean centered by column. The coefficient of rectilinearity of particle motion is equal to $1-\left(\lambda_{2}+\lambda_{3}\right) /\left(2 \lambda_{1}\right)$, where $\lambda_{1}, \lambda_{2}$, and $\lambda_{3}$ are the eigenvalues of the covariance matrix and $\lambda_{1}>\lambda_{2}>\lambda_{3}$ [e.g., Bokelmann, 1995]. The rectilinearity is equal to 1 for linear polarization and close to 0 for an almost circular polarization. We considered only signals with a rectilinearity of particle motion higher than 0.90. An example of $P$ wave polarization measurement is given in Figure 1. The uncertainty for each $P_{\text {pol }}$ measurement (horizontal polarization) is estimated by $\arctan \left(\left(\lambda_{2} / \lambda_{1}\right)^{1 / 2}\right)$. We rejected all observations with uncertainty on the horizontal polarization higher than $10^{\circ}$.

[14] At each station, we divided the measurements into back azimuthal bins of $20^{\circ}$ and calculated the median value in 
every bin containing more than 5 measurements. Since we had not enough observations in each $20^{\circ}$ bin at PPTL to calculate the median value in every bin containing more than 5 measurements, we chose to determine the median value in every bin of $20^{\circ}$ containing at least 4 measurements. The scaled median average deviation (SMAD) [Bevington and Robinson, 1969] provides a measure of the error for each bin. If a station is characterized by data in at least three back azimuthal $(\theta)$ quadrants, we use a harmonic analysis by fitting the following function [Schulte-Pelkum et al., 2001] to the data:

$$
\delta \theta=A_{1}+A_{2} \sin \theta+A_{3} \cos \theta+A_{4} \sin 2 \theta+A_{5} \cos 2 \theta
$$

We determined $A_{1}, A_{2}, A_{3}, A_{4}$ and $A_{5}$ by a multiple linear regression. The constant $A_{1}$ provides an estimate of the misorientation; $A_{2}$ and $A_{3}$ depend on lateral heterogeneity, especially dip of interfaces, but also a potential dip of anisotropic axes. $A_{4}$ and $A_{5}$ characterize the effect of anisotropy under the station, for the case of a horizontal symmetry axis. We determine the fast axis orientation $\left(\theta_{\text {fast }}\right)$ using a harmonic analysis from the phase of the $2 \theta$ component.

$$
\theta_{\text {fast }}=\frac{1}{2} \arctan \frac{A_{4}}{A_{5}}+\frac{\pi}{4}
$$

The term $(1 / 2) \arctan \left(A_{4} / A_{5}\right)$ gives the value of $\theta$ for which the function $A_{4} \sin (2 \theta)+A_{5} \cos (2 \theta)$ is maximum. In an anisotropic medium with a horizontal axis of symmetry the maximum polarization deviation occurs near $45^{\circ}$ from the fast axis [Schulte-Pelkum and Blackman, 2003]. Therefore, the fast direction is obtained by adding $\pi / 4$ to the value of $(1 / 2) \arctan \left(A_{4} / A_{5}\right)$.

[15] The amplitude of the effect of anisotropy is given as

$$
\delta \theta_{\max }=\sqrt{A_{4}^{2}+A_{5}^{2}}
$$

The amplitude ascribed to heterogeneity and dipping is

$$
\delta \operatorname{dip}_{\max }=\sqrt{A_{2}^{2}+A_{3}^{2}}
$$

In order to better constrain the effect of dipping and anisotropic structures beneath our selected seismic stations, we developed two other independent modeling approaches of such effects (a grid search and an inversion with a neighborhood algorithm). These approaches allow us to check the results of the harmonic analysis and to estimate the individual effects of the seismic sensor misorientation, the presence of dipping structures and the upper mantle anisotropy on $P_{\mathrm{pol}}$.

\section{Modeling $\boldsymbol{P}$ Wave Polarization Deviation in Dipping Structures}

[16] If $\delta \theta_{\max } \geq \delta \operatorname{dip}_{\max }$, then anisotropy is considered to be more important for explaining the deviation pattern than dipping interfaces. Otherwise, it may be sufficient to fit the data with a model that incorporates just a dipping seismic discontinuity and a sensor misorientation.

[17] We constructed a simple single-interface model using Snell's law characterized by interface dip, strike, and $P$ velocity contrast $\left(V_{\text {upper }} / V_{\text {lower }}\right)$ to evaluate the presence of a dipping structure beneath the receiver when $\delta \theta_{\max } \leq$ $\delta \operatorname{dip}_{\max }$. The method to compute the polarization deviation associated with a dipping discontinuity is described elsewhere [Niazi, 1966; Brown, 1972]. The apparent value $\theta_{\text {calc }}$ of the azimuth of a $P$ wave at the surface:

$$
\theta_{\text {calc }}=\arctan \left(l_{0} / m_{0}\right)+\gamma
$$

where $\gamma$ is the azimuth of updip direction of the dipping interface and $l_{0}$ and $m_{0}$ are direction cosines of a $P$ ray in each single-interface model.

[18] We used a grid search technique to evaluate the presence of a dipping seismic discontinuity beneath the receiver. We found the preferred model minimizing a $L_{1}$ norm misfit function. We found that an exponential distribution was more appropriated to describe our data set; the $L_{1}$ norm is more robust than the $L_{2}$ norm when excessive outliers are present in the data [e.g., Shearer, 1999]. Figure 2a shows an example of misfit function. We minimize the sum of absolute residuals as

$$
E=\sum_{i=1}^{N}\left|\theta i^{\text {obs }}-\theta i^{\text {calc }}\right|
$$

where $N$ is the number of observations, $\theta^{\text {obs }}$ is the $P_{\text {pol }}$ observations, and $\theta^{\text {calc }}$ is the predicted value. In equation (6), we assume that uncertainties on data are uncorrelated and constant. The best model is obtained by choosing the minimum misfit for an incidence angle close to $P_{\text {pol }}$ observations.

[19] The direction of dip is determined using the rule formulated by Niazi [1966]: if horizontal polarization deviations are read clockwise, the direction of dip is the point of transition from negative to positive values; otherwise, the direction is the point of transition from positive to negative. This method does not provide any constraint on the thickness of the layers.

[20] We computed synthetic waveforms for our preferred model with a dipping discontinuity and remeasured the $P$ wave polarization measurements on the synthetics in order to compare the predicted polarization deviations of our best model with the observed deviations. We did this to check the result from the grid search using Snell's law. We used a method developed by Frederiksen and Bostock [2000] for modeling teleseismic waves in dipping anisotropic structures. This modeling can be applied only to teleseismic waves in the upper mantle and crust.

\section{Modeling $P$ Wave Polarization Deviation in Anisotropic Structures}

[21] If $\delta \theta_{\max } \geq \delta \operatorname{dip}_{\max }$, then we perform an inversion of $P_{\text {pol }}$ observations for anisotropic upper mantle structures using a neighborhood algorithm [Sambridge, 1999]. As discussed earlier in this paper, for $P$ waves propagating in a weakly anisotropic material the particle motion can be described to first order as $g(\Phi)=C_{1} \sin 2 \Phi$ [Davis, 2003]. This function $g(\Phi)$ has a $180^{\circ}$ periodicity. During the forward modeling of the neighborhood algorithm we used the method developed by Frederiksen and Bostock [2000] for computing synthetic teleseismic waves in dipping anisotropic structures. We considered the sensor misorientation obtained from the 

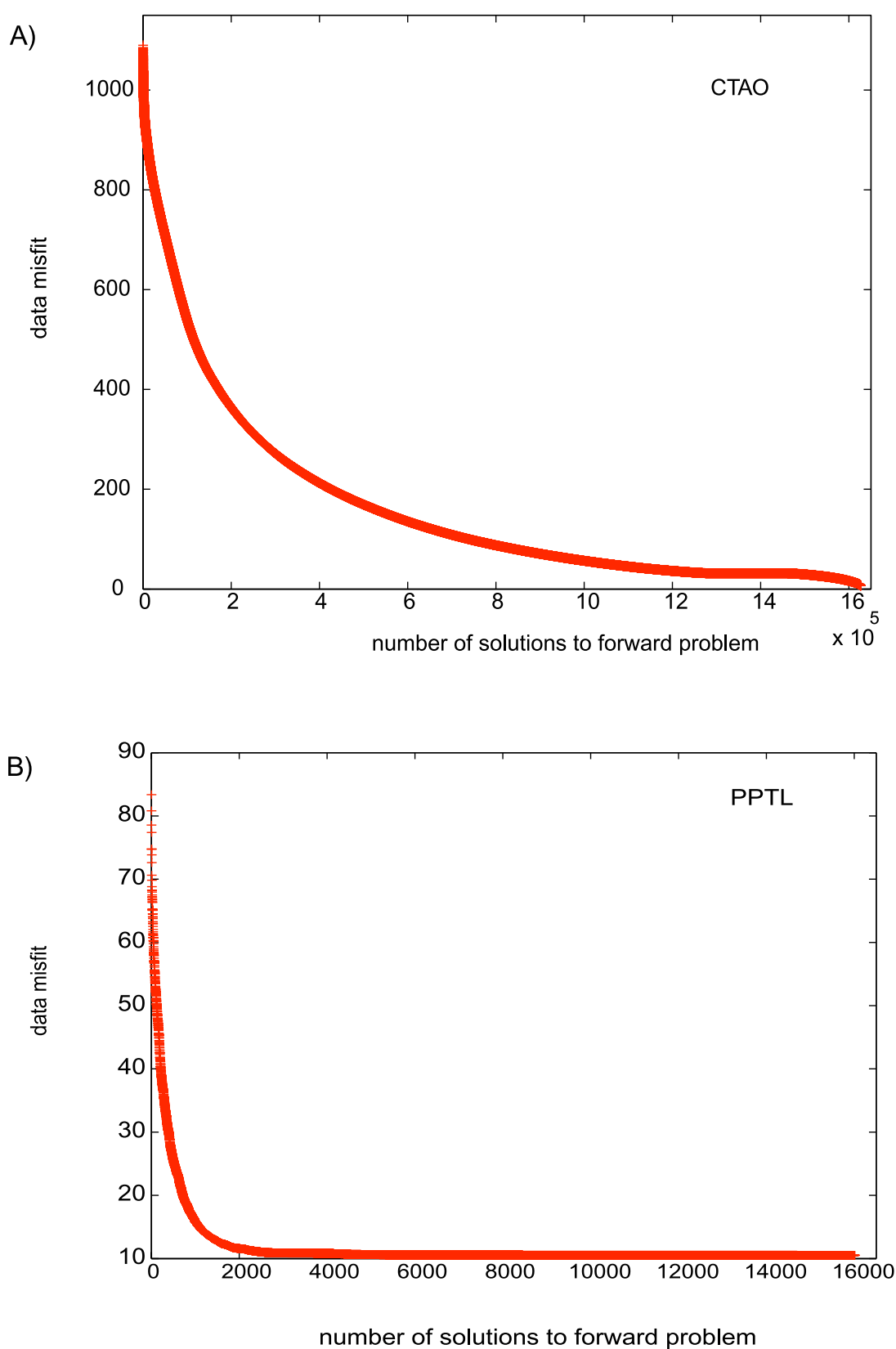

Figure 2. Misfit function against number of models for which the forward problem has been solved. (a) Misfit produced by the grid search using Snell's law at CTAO. (b) Misfit function obtained using the NA algorithm from horizontal polarization deviation observed at PPTL.

harmonic analysis when we evaluated the misfit function. A $L_{1}$ norm misfit function is used to measure the difference between the calculated, $\theta^{\text {calc }}$, and observed, $\theta^{\text {obs }}$, polarization direction. We use a similar $L_{1}$ norm misfit function as in equation (6). Figure $2 \mathrm{~b}$ shows an example of misfit function.

[22] The neighborhood algorithm (NA) is a direct search method of inversion. It has the capacity to search efficiently by sampling simultaneously different regions of parameter space. This inversion technique samples regions of a multidimensional parameter space that have acceptable data fit. The NA makes use of simple geometrical concepts to search a parameter space. At each iteration the entire parameter space is partitioned into a set of Voronoi cells [Voronoi, 1908] constructed about each previously sampled model. In our case, Voronoi cells are nearest neighbor regions defined by an $L_{1}$ norm. The initial sets of samples are uniformly random, but as iterations proceed, only a subset of chosen Voronoi cells is resampled (using a random walk within each cell). This allows the NA algorithm to concentrate where data misfit is lowest. A further advantage of the NA over other direct search methods is that only the rank of the misfit function is used to compare models. This is of particular significance as it avoids problems associated with scaling of the misfit function and allows any type of user-defined misfit measure to be employed. The NA requires just two control parameters: $n_{s}$, which is the number of models generated at each iteration, and $n_{r}$, which is the number of neighborhoods resampled at each iteration. 
Table 1. Results From the Harmonic Analysis ${ }^{a}$

\begin{tabular}{|c|c|c|c|c|c|c|c|c|c|c|}
\hline Station & $A_{1}$ & $A_{2}$ & $A_{3}$ & $A_{4}$ & $A_{5}$ & $\theta_{\text {fast }}(\mathrm{deg})$ & $\theta_{\max }(\mathrm{deg})$ & $\theta_{\min }(\mathrm{deg})$ & $\delta \mathrm{dip}_{\max }$ & $\delta \theta_{\max }$ \\
\hline CAN & $1.55 \pm 0.40$ & $-2.63 \pm 0.58$ & $-1.56 \pm 0.56$ & $-1.42 \pm 0.53$ & $-0.65 \pm 0.56$ & -12.29 & -5.80 & -58.25 & 3.06 & 1.56 \\
\hline CTAO & $-1.64 \pm 0.52$ & $3.58 \pm 0.78$ & $2.42 \pm 0.66$ & $0.63 \pm 0.76$ & $0.62 \pm 0.49$ & 67.62 & 80.84 & 22.43 & 4.32 & 0.89 \\
\hline TAU & $1.79 \pm 0.30$ & $3.00 \pm 0.75$ & $0.73 \pm 0.30$ & $-3.59 \pm 0.62$ & $-0.40 \pm 0.33$ & -3.21 & -1.62 & -42.00 & 3.08 & 3.61 \\
\hline NWAO & $-5.01 \pm 0.48$ & $-0.62 \pm 0.67$ & $1.47 \pm 0.79$ & $1.12 \pm 0.65$ & $-0.28 \pm 0.74$ & 96.98 & 176.83 & 91.68 & 1.38 & 5.10 \\
\hline PPTL & $-3.13 \pm 1.37$ & $-1.37 \pm 0.99$ & $-0.23 \pm 2.30$ & $5.06 \pm 1.04$ & $0.58 \pm 1.97$ & 86.75 & 89.29 & 1.24 & 1.39 & 5.10 \\
\hline
\end{tabular}

${ }^{\text {a }}$ Coefficients of the equation (1) used to fit the $P_{\text {pol }}$ observations at CAN, CTAO, NWAO, TAU, and PPTL. $A_{1}$ is the value indicating the sensor misorientation in degrees; $\theta_{\text {fast }}$ is the fast axis orientation; $\theta_{\max }$ is equal to $\theta_{\text {fast }}+\Delta \theta$; and $\theta_{\min }$ is equal to $\theta_{\text {min }}-\Delta \theta$.

[23] The NA exploits the self-adaptive behavior of Voronoi cells. Voronoi cells are nearest neighbor regions defined by suitable distance norms [Voronoi, 1908]. We specify a maximum number of iterations (i.e., 1000 for PPTL and 1000 for TAU) and take the best fitting solution found as our preferred model. We perform $P_{\text {pol }}$ inversion using the NA for the following model parameters: the thickness of the layer, percentage anisotropy, azimuth and plunge of fast axis. In our inversion, the top layer (i.e., first layer) corresponds to the crust, the second and third layer are the two anisotropic layers suggested by seismic tomography beneath Tahiti (i.e., the lithosphere and the asthenosphere) and the fourth layer was assumed to be the underlying half-space. To perform the inversion of $P_{\mathrm{pol}}$ observations at TAU, we considered a model with three horizontal layers, since only one anisotropic layer was suggested in the upper mantle by surface wave tomography of Debayle et al. [2005] beneath Tasmania. On the other hand, we used four horizontal layers for modeling PPTL data because recent surface wave tomographic study of the South Pacific evidenced the presence of two anisotropic layers in the upper mantle for depth between 50 and $200 \mathrm{~km}$ [Maggi et al., 2006]. The thickness of the crust beneath PPTL $(11 \mathrm{~km})$ and velocities are fixed from values determined by receiver functions at PPT [Leahy and Park, 2005].

[24] During the inversion, the model comprises four parameters to be determined in the second layer of TAU and four parameters to be determined in both the second and third layer of PPTL (i.e., eight unknown parameters for this station). For each parameter, we specify the upper and lower bounds to set up the search volume for the NA. For the magnitude of anisotropy the search was restricted to $1-11 \%$; for the azimuth of fast anisotropic axis we searched between $0^{\circ}$ and $360^{\circ}$ (degree clockwise, from the north) and for the plunge of fast axis we restricted our search between $0^{\circ}$ and $30^{\circ}$. The layer thickness has been bounded between $10 \mathrm{~km}$ and $250 \mathrm{~km}$ for TAU. The layer thicknesses are between $40 \mathrm{~km}$ and $100 \mathrm{~km}$ for the second layer and between $10 \mathrm{~km}$ and $140 \mathrm{~km}$ for the third layer of PPTL model. After several trials we fixed $n_{s}=16$ and $n_{r}=8$.

\section{Results}

[25] For the four permanent Australian seismic stations (TAU, CAN, NWAO, and CTAO) and the permanent station in Tahiti (PPTL), there is sufficient coverage in three back azimuthal quadrants, which is required to resolve the azimuthal dependence. The results of the harmonic analysis are summarized in Table 1. The first result from this analysis is that the amplitude of anisotropy is higher than the amplitude associated with dipping at stations TAU, NWAO, and PPTL (i.e., $\delta \theta_{\max } \geq \delta$ dip $p_{\max }$ ) which is not the case for stations CTAO and CAN therefore suggesting an important influence of dipping layers beneath CAN and CTAO stations. We describe below the results obtained at each of these stations, by analyzing first the anisotropy signal and then the possible existence of dipping layers and the station misorientation that has been deduced from our analysis.

[26] The fast anisotropic orientation found at CAN $\left(-12.29^{\circ}\right)$ is close to the orientation obtained by SchultePelkum et al. [2001]: $-16.47 \pm 14.34^{\circ}$, however, since we found that $\delta \operatorname{dip}_{\max } / \delta \theta_{\max }=1.96$, we conclude that anisotropy cannot alone explain the entire signal. Therefore, the dipping contribution appears to be the most important effect at CAN. The best dipping model obtained at CAN is for an incidence angle of $45^{\circ}$, a dip of $19^{\circ}$, a $P$ wave speed contrast ( $V_{\text {upper }} /$ $V_{\text {lower }}$ ) of 1.1 and a strike of $238^{\circ}$. We propose a small misorientation of $1.55 \pm 0.40^{\circ}$ for this sensor (Table 2).

[27] The fast axis orientation obtained in this study at CTAO $\left(67.62^{\circ}\right)$ is different from that of Schulte-Pelkum et al. [2001]: $16.51 \pm 14.83^{\circ}$. We note, however, that this station has the smallest $\delta \theta_{\max }$ among the stations in the study, and the largest $\delta \operatorname{dip}_{\max }$ (Table 1). We expect that the effect of dip may map into the determination of anisotropy for smaller data sets with weaker back azimuthal coverage. With a ratio $\delta \operatorname{dip}_{\max } /$ $\delta \theta_{\max }$ of 4.88 , the influence of dipping interfaces at this station is expected to be strong. The best dipping model at CTAO is for an incidence angle of $65^{\circ}$, a dip of $9^{\circ}$, a $P$ velocity contrast $=0.8$, and a strike of $240^{\circ}$, rather close to the one observed at CAN (Table 2). The observed $P$ wave polarization deviations are compared to our preferred model in Figures 3 and 4. The ensemble of parameters for the 10,000 best models over 1,620,000 models tested with a grid search using Snell's law are represented in Figures 5 and 6. Our misorientation is slightly smaller than for Schulte-Pelkum et al. [2001] at CTAO: $-1.64 \pm 0.52^{\circ}$ instead of $-2.7^{\circ}$.

[28] The azimuth of the fast axis obtained at TAU $\left(-3.21^{\circ}\right)$ is consistent with the measurement of Schulte-Pelkum et al. [2001]: $178.74 \pm 31.36^{\circ}$ (i.e., $-1.26^{\circ}$ because of the $180^{\circ}$

Table 2. Best Fitting Model Parameters Used for Modeling the Horizontal Deviation With Snell's Law at CTAO and CAN

\begin{tabular}{lccccr}
\hline Station & $V_{P}$ Contrast & Strike $($ deg$)$ & Dip $($ deg $)$ & $I_{2}($ deg $)$ & Misor $($ deg) \\
\hline CAN & 1.1 & 238 & 19 & 45 & 1.55 \\
CTAO & 0.8 & 240 & 9 & 65 & -1.64 \\
\hline
\end{tabular}

${ }^{\text {a }}$ Layers are listed from top to bottom. Strike and dip refer to the upper interface of the layer. $V_{P}$ velocity contrast is the ratio of $P$ wave velocities: $V_{\text {upper }} / V_{\text {lower }}$. Misor is the value of the sensor misorientation obtained from the harmonic analysis. $I_{2}$ is the incidence angle of the ray in the lower layer. We add Misor to the value of $\theta_{0}$ obtained from equation (5) to compute the polarization deviation in dipping structures. 
A)

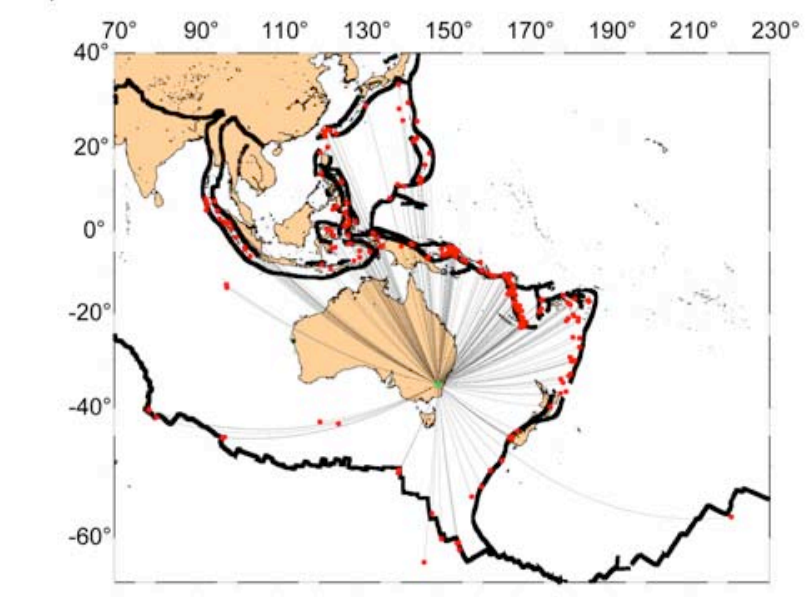

B)

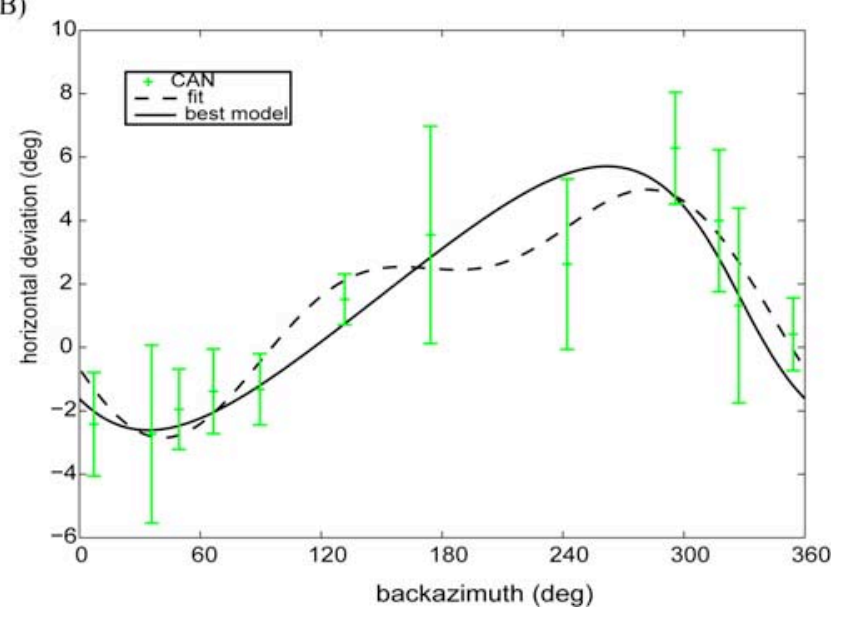

Figure 3. (a) Location of 238 events used for $P_{\text {pol }}$ deviation measurements at station CAN. (b) Variation of the horizontal deviation of the $P$ wave polarization as a function of the event back azimuths. The crosses represent the observed binned values together with their error bars that correspond to scaled median average deviation (SMAD) values. SMAD is preferred to standard deviation because it is less sensitive to outliers. The black curve is the predicted horizontal deviation for the best isotropic model with dipping seismic discontinuity. That model has a dip of $19^{\circ}$, a strike $238^{\circ}$, and $P$ velocity contrast of 1.1 . The dashed curve shows the fit with the harmonic analysis (equation (1)).

ambiguity in the sense of the fast axis). At this station, $\delta \theta_{\max } \geq \delta$ dip $_{\max }$, suggesting that the effect of anisotropy dominates the signal. The misorientation observed in this study at TAU $\left(1.79 \pm 0.30^{\circ}\right)$ is slightly lower than the one obtained by Schulte-Pelkum et al. [2001]: $2.1^{\circ}$. The observed $P$ wave polarization deviations at TAU are compared to our preferred model in Figure 7. Our preferred model for this station is a dominating contribution of asthenospheric flow induced by the northward present-day plate motion of the Australian plate. Figure 8 shows an ensemble of 16,000 models generated by the NA algorithm. The best model corresponds to a global minimum.

[29] We measured a fast axis orientation of $96.98^{\circ}$ at NWAO, whereas Schulte-Pelkum et al. [2001] obtained a value of $154.40^{\circ} \pm 9.62^{\circ}$ at this station. We consider not reliable our measurement of the fast axis azimuth at NWAO as the values obtained for the SMAD in each bin are too high compared with the polarization deviation. $80 \%$ of data (horizontal deviations of polarization direction) are with uncertainties ranging from $\pm 3^{\circ}$ to $\pm 5^{\circ}$ (i.e., up to $10^{\circ}$ of variation in a bin) whereas $P_{\text {pol }}$ observations are in the range $-2.2^{\circ}$ to $-7.3^{\circ}$. The misorientation observed in this study at NWAO is $-5.01^{\circ} \pm 0.48^{\circ}$ which is close to the result of Schulte-Pelkum et al. [2001]: $-5.80^{\circ}$.

[30] The observed $P$ wave polarization deviations at PPTL are compared to our preferred model in Figure 9. Figure 10 shows the models generated by the NA projected onto six pairs of axes. The best solution corresponds to a global minimum. Our preferred model at this station obtained from inversion of $P_{\mathrm{pol}}$ observations (Table 3 ) corresponds to two layers of anisotropy beneath an isotropic crust. The fast axis orientation is $270^{\circ}$ (i.e., orientation E-W) in the upper layer and $137^{\circ}$ in the lower layer. The percentage of anisotropy is high in the upper layer: $10 \%$. We observe that the fast axis azimuth is well resolved in the layer 2 whereas it is not well resolved in layer 3 (Figure 10). The percentage anisotropy is also well determined in layer 2 whereas it is not well determined in layer 3 . The fast axes are not horizontal in the upper and lower layer. The plunge we determined is of $6^{\circ}$ in the upper layer and $13^{\circ}$ in the lower layer. At PPTL, we propose a misorientation of the sensor of $-3.13 \pm 1.37^{\circ}$.

\section{Discussion}

\subsection{Dipping Structures and Anisotropy Beneath Australia}

[31] Station CAN is located on Mount Stromlo in the Lachlan Fold Belt. Our measurements show that the $P_{\mathrm{pol}}$ horizontal deviation pattern at CAN is mostly explained by a dipping interface $\left(360^{\circ}\right.$ of periodicity) with a strike of $238^{\circ}$. Most of the deviation signal can be explained without invoking anisotropy. This dipping structure observed at CAN is consistent with results from receiver functions. A well-defined low-velocity zone in the crust was observed at depth $\sim 15-20 \mathrm{~km}$ by seismic investigations of Finlayson et al. [1980] in the Lachlan Fold Belt with a $P$ velocity contrast of $\sim 1.06$. A seismic discontinuity was imaged around $20 \mathrm{~km}$ depth (possibly Conrad which is a midcrustal discontinuity of continental crusts) beneath the Lachlan Fold Belt [Clitheroe et al., 2000a]. Previous receiver function studies and seismic reflection experiments in southeastern Australia [Collins, 1991; Shibutani et al., 1996; Clitheroe et al., 2000b] shows a Mohorovičić discontinuity (Moho) dipping toward the SE beneath Canberra with a strike close to $238^{\circ}$ [Clitheroe et al., 2000b, Figure 9]. This dip could be related to the "root" of the Lachlan Fold Belt. $P_{\mathrm{pol}}$ observations suggest a similar dipping orientation for a discontinuity in the crust, possibly Conrad.

[32] The fast axis orientation we observe at CAN $\left(-12.29^{\circ}\right)$ is compatible with the orientation found by Girardin and Farra [1998] in a lower layer, $40 \mathrm{~km}$ thick, located in the upper mantle. This orientation is not far from the orientation $\mathrm{N}-\mathrm{S}$ observed between 175 and $300 \mathrm{~km}$ depth by surface wave tomography [Debayle et al., 2005]. It is very close to the present Australian plate motion direction in the absolute hot spot reference frame at CAN: $-8.6^{\circ}$ [Gripp and Gordon, 2002]. This apparent azimuthal anisotropy may be due to 
A)

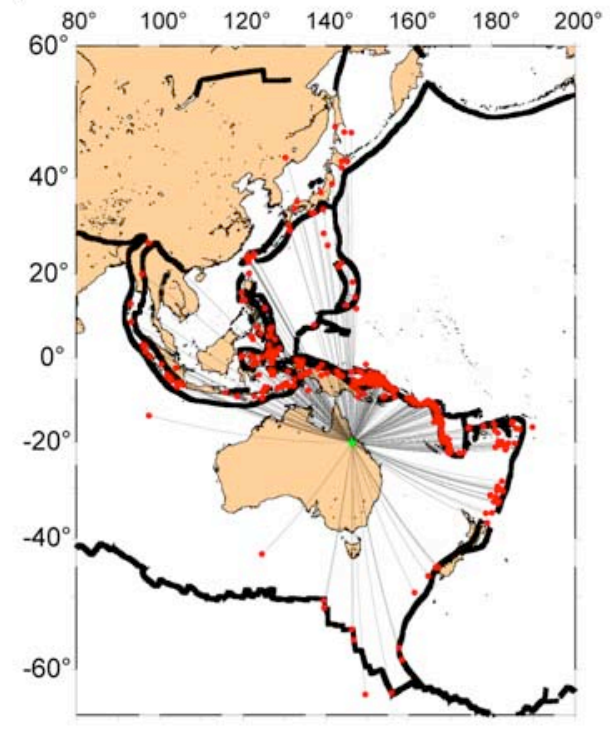

C)

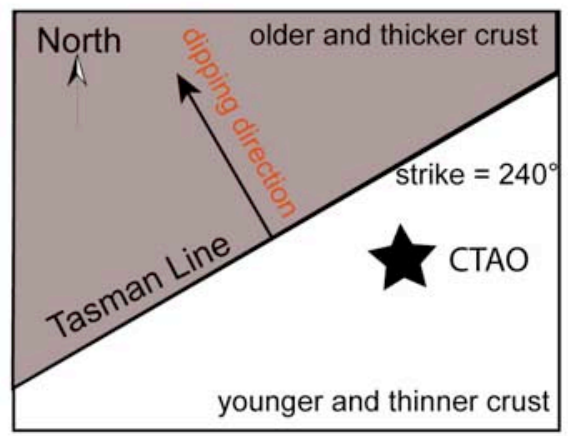

B)

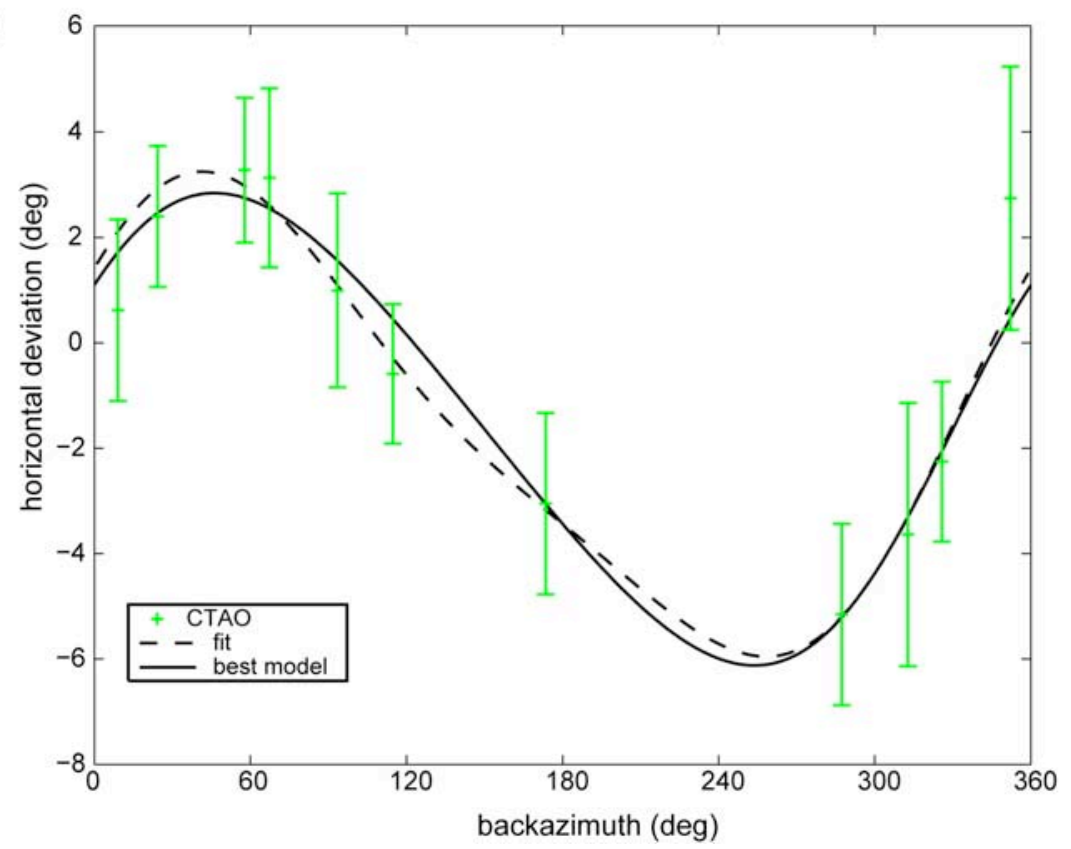

Figure 4. (a) Location of 402 events used for $P$ wave polarization deviation measurements at station CTAO. (b) Comparison of observed azimuthal average polarization deviation at station CTAO with predicted values for our preferred model. The best model (black curve) is characterized by a seismic discontinuity with a dip of $9^{\circ}$ toward the southeast beneath the receiver. The strike of the discontinuity is $240^{\circ}$. The $P$ velocity contrast is 0.8 . The dashed curve shows the fit obtained with the harmonic analysis (equation (1)). Parameters of the fit with the harmonic analysis are in Table 1. Error bars correspond to SMAD values. (c) Cartoon showing our interpretation of the best model obtained by the grid search at CTAO. CTAO is located around $250 \mathrm{~km}$ from the transition in the crustal thickness that may be associated with the Tasman Line. Our best model is characterized by a dip toward the NW compatible with a transition from a thick crust beneath central Australia to a thinner crust beneath eastern Australia.

crystal-preferred orientation of olivine produced by deformation in the sublithospheric mantle due to viscous entrainment by the moving plate. Interestingly, this observation of a $\mathrm{N}-\mathrm{S}$ trending anisotropy located at asthenospheric depth is also consistent with the apparent isotropy deduced from $S K S$ splitting at CAN [Barruol and Hoffmann, 1999] that was proposed to be a combined effect of an asthenospheric layer with a $\mathrm{N}-\mathrm{S}$ trending fast axis underlying a lithospheric upper layer with a roughly $\mathrm{E}-\mathrm{W}$ trending fast orientation that would physically remove the splitting acquired in the lower layer. Surface wave tomography [Debayle et al., 2005] propose the same interpretation with $\mathrm{N}-\mathrm{S}$ (below) and $\mathrm{E}-\mathrm{W}$ 
Results from the grid-search at CAN
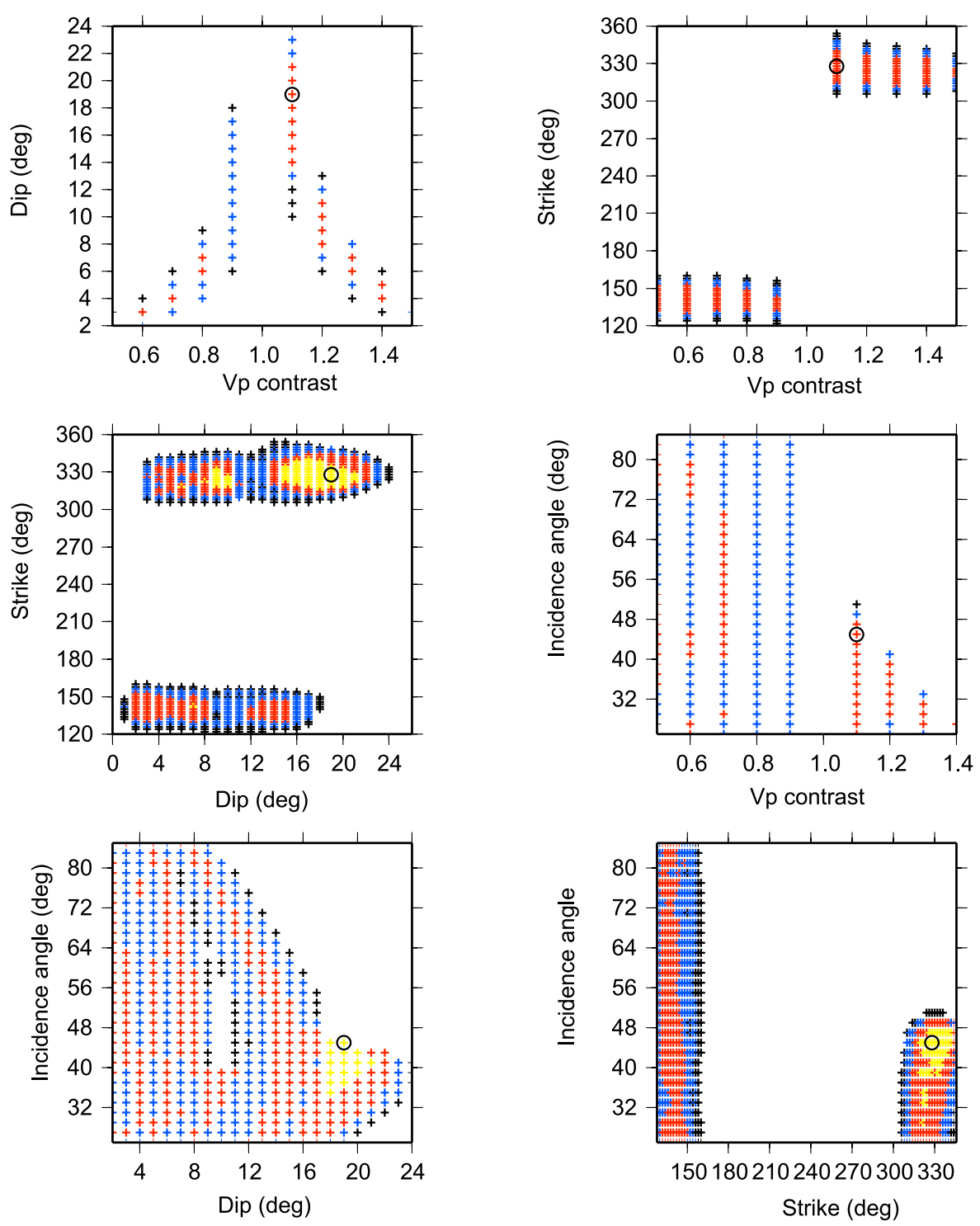

Figure 5. The 10,000 best models produced by the grid search from measurements at CAN. The best of the 10,000 models is shown as a circle. The crosses are colored from black through blue then red to yellow, as the data fit increases.

trending (above) anisotropic layers beneath the Australian continent.

[33] At CTAO we observe a similar periodicity of $360^{\circ}$ in the horizontal deviation pattern suggesting the presence of a dipping seismic discontinuity beneath the receiver. CTAO is located $\sim 250 \mathrm{~km}$ from a transition in crustal thickness that may be associated with the Tasman Line [see Clitheroe et al., 2000b, Figure 9]. The Tasman Line is a transition from the thick crust beneath central Australia to the thinner crust beneath eastern Australia [Clitheroe et al., 2000b]. The $\mathrm{NE}-\mathrm{SW}$ orientation of this transition is close to the strike of the dipping seismic discontinuity: $240^{\circ}$ (Figure 4c). Our best model is characterized by a dip toward the NW, therefore compatible with the dip of a crustal structure. Therefore, $P_{\mathrm{pol}}$ observations are consistent with receiver function studies.
[34] Our fast azimuth orientation obtained at TAU $\left(-3.21^{\circ}\right)$ is close to the present Australian plate motion direction at TAU: $-8.9^{\circ}$. The $180^{\circ}$ periodicity pattern and the amplitude of anisotropy observed for this station suggest that anisotropy explains most of the observed deviation of polarization. This apparent azimuthal anisotropy may be due to olivine crystal preferred orientations produced by deformation in the sublithospheric mantle due to viscous entrainment by the moving plate.

\subsection{Differentiation Between Anisotropy and Dipping Effects}

[35] We differentiate between the two end-member cases (effect of anisotropy or effect of dipping) based on the ratio $\delta \operatorname{dip}_{\max } / \delta \theta_{\max }$. In the cases of CTAO, CAN, and PPTL the 
Results from the grid-search at CTAO
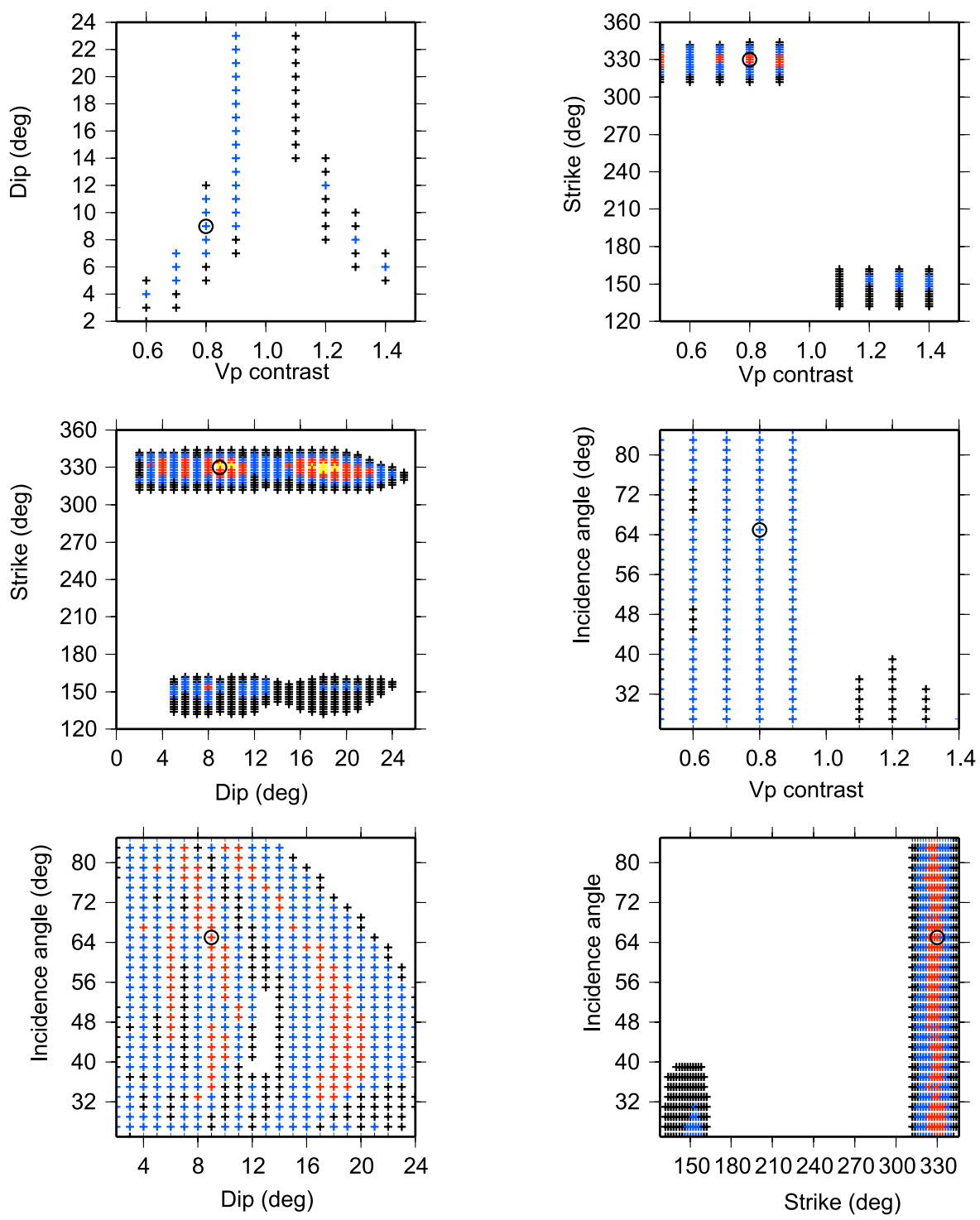

Figure 6. The 10,000 best models produced by the grid search from measurements at CTAO. The best of the 10,000 models is shown as a circle. The crosses are colored from black through blue then red to yellow, as the data fit increases.

relative amplitudes differ by a factor of 2 or greater which indicates a much significant effect of one of the end-member. However, at TAU, $\delta \operatorname{dip}_{\max } / \delta \theta_{\max }$ is around 0.85 which indicates $15 \%$ lower amplitude for dipping discontinuity influence. We realized a grid search for dipping discontinuity beneath TAU. The 2000 best models obtained from this grid search have a $P$ wave speed contrast of 1 which suggests no seismic discontinuity beneath the seismic station. We also observed a bad correlation between the predicted $P$ wave polarization deviation for the best models and the observed $P$ wave polarization deviation. On the other hand, the best model obtained from the NA inversion provide a good fit of the observations (Figure 7) and the best model corresponds to a well constrained global minimum (Figure 8). The present data set could be adequately fitted by one of the end-member: dipping effect or anisotropic effect.

\section{3. $S K S-P_{\mathrm{pol}}$ Apparent Discrepancy Beneath Tahiti}

[36] Despite the availability of 15 years of data, the two permanent seismic stations on Tahiti (PPT and PPTL installed in the same seismic vault) do not show any evidence of shear wave splitting [Fontaine et al., 2007]. On the other hand, $P_{\text {pol }}$ observations show clear azimuthal variations that are strongly suggestive of upper mantle seismic anisotropy. The high value of percentage anisotropy obtained in the upper layer $(10 \%)$ from the NA inversion is not unrealistic since lherzolite and harzburgite rock samples brought to the surface by the Society hot spot volcanism from French Polynesia display $P$ wave azimuthal anisotropy between 9 and $11 \%$ and $S$ wave azimuthal anisotropy in the range 5-7\% [Tommasi et al., 2004]. Our preferred model obtained from inversion of $P_{\mathrm{pol}}$ observations corresponds to two layers of anisotropy beneath an isotropic crust. The fast axis orientation is $\mathrm{E}-\mathrm{W}$ in 


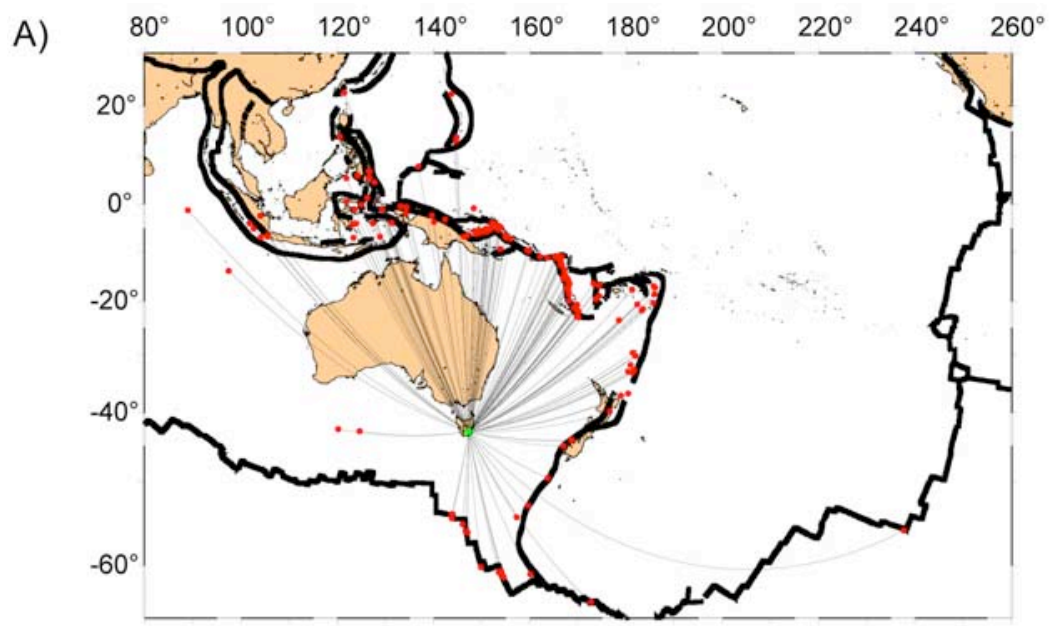

B)

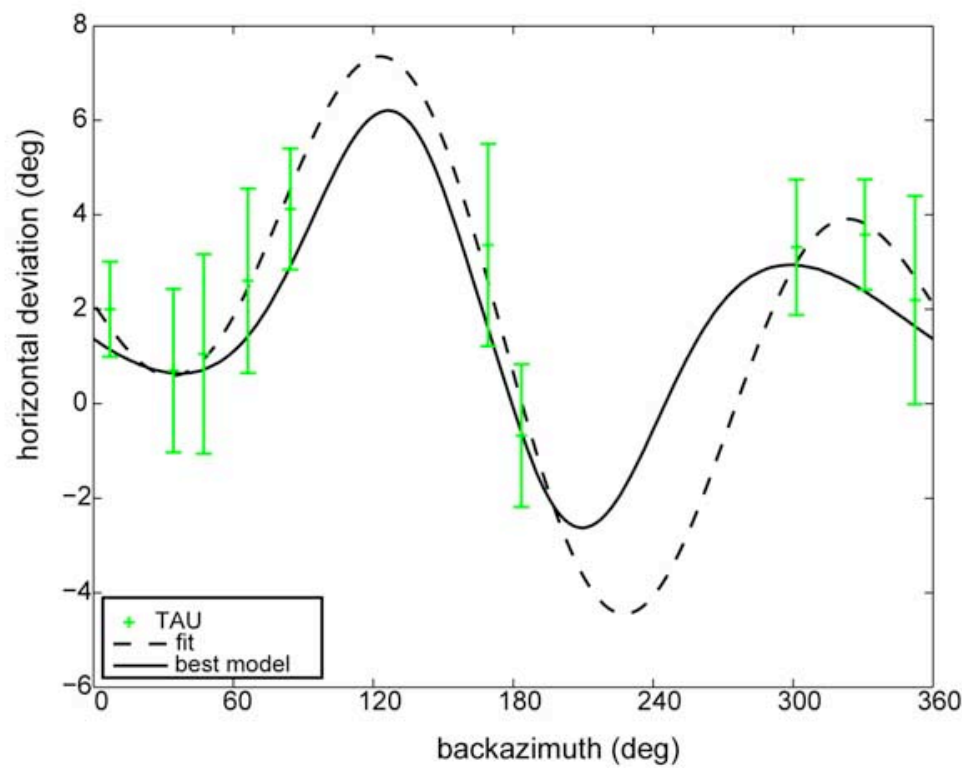

Figure 7. (a) Location of 157 events used at station TAU. (b) Azimuthal polarization deviations observed at station TAU compared with the predicted values for our best model including anisotropy (black curve). This preferred model was obtained using the NA for one anisotropic layer in the upper mantle and a sensor misorientation. The dashed curve shows the fit with the harmonic analysis (equation (1)). Parameters of the fit with the harmonic analysis are listed in Table 1. Error bars correspond to SMAD values.

the upper layer and $137^{\circ}$ in the lower layer. Figure 11 provides a possible explanation of this apparent paradox. On one hand, the $S K S / S K K S$ waves travel along an almost vertical path and may sample the mantle upwelling associated with the Society hot spot, characterized either by vertical olivine $a$ axes [100] or by a large presence of melt in the upper mantle or more simply by a structure strongly perturbed by the hot spot processes that render the medium isotropic at the scale of the $S K S$ waves. On the other hand, the $P$ waves do not sample the same upper mantle structure due to their larger incidence angles. The combination of the absence of SKS splitting together with clear $P_{\text {pol }}$ deviations may help to constrain the size of the perturbed lithospheric structures due to its interaction with the Society hot spot. By taking into account the maximum incidence angle of $S K S$ waves and the minimum incidence angle of $P$ waves, we determine the maximum radius of the hot spot that may affect the upper mantle beneath PPTL and explain both the isotropic $S K S$ behavior and the $P_{\mathrm{pol}}$ deviation (as schematized in Figure 11). Such simple calculation provides a maximum radius of perturbed upper mantle of $35.8 \mathrm{~km}$ at $100 \mathrm{~km}$ depth and $39.2 \mathrm{~km}$ at $270 \mathrm{~km}$ depth. Such values are fully compatible with plume diameters deduced from numerical modeling [Thoraval et al., 2006]. The fast anisotropic orientation deduced from the harmonic analysis at Tahiti $\left(86.75^{\circ}\right)$ is close to the fast axis orientation $(\mathrm{E}-\mathrm{W})$ found in the upper layer from the inversion of $P_{\mathrm{pol}}$ measurements. We propose that this orientation is related to the large-scale anisotropy of the lithosphere (about $100 \mathrm{~km}$ thick in this area of the Pacific). The lithospheric mantle younger than $20-25 \mathrm{Ma}$ is possibly characterized by olivine $a$ axes homogeneously oriented parallel to the current Pacific absolute plate motion (APM) direction whereas the lithospheric mantle older than 25 Ma has fossilized olivine $a$ axes oriented parallel to the paleoexpansion direction [Fontaine et al., 2007]. This possibility may explain the fact that the fast anisotropic orientation is $\mathrm{E}-\mathrm{W}$, an orientation 

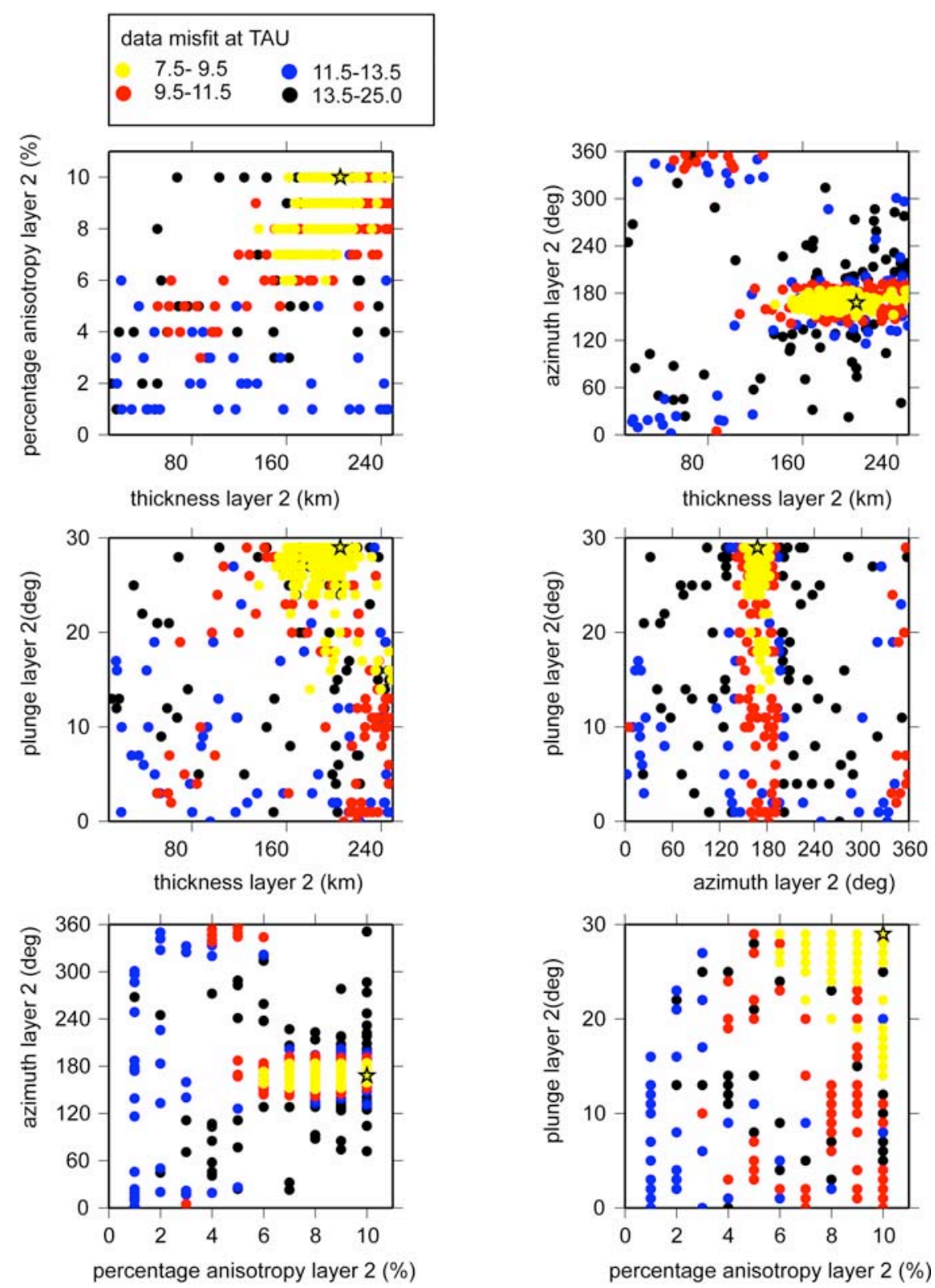

Figure 8. Results from the NA inversion at TAU. We searched for one layer of anisotropy with four unknown parameters. Models produced by the NA algorithm, projected onto six pairs of axes. Each plot shows the projection of the 4-D parameter space onto a 2-D plane. The circles are colored from black through blue then red to yellow, as the data misfit decreases. The star indicates the model found with best data fit.

midway between the local APM direction and the fossil spreading direction (around $75^{\circ}$ ). The origin of the lithospheric, fossil anisotropy is explained by Fontaine et al. [2007, section 4.3]. The fast axis orientation deduced from $P_{\text {pol }}$ is also consistent with the observed fast axis orientations within the lithosphere from a surface wave tomographic model in the vicinity of Tahiti at $50 \mathrm{~km}$ depth [e.g., Maggi et al., 2006]. The fast axis orientation $\left(137^{\circ}\right)$ obtained in the lower layer from the inversion of $P_{\mathrm{pol}}$ measurements is also consistent with a surface wave tomographic model which shows in the southern part of the Pacific a fast azimuth at $100 \mathrm{~km}$ depth trending NW-SE [e.g., Maggi et al., 2006]. Interestingly, $S K S$ splitting observed at the other stations deployed in French Polynesia for the PLUME experiment showed evidence of clear anisotropy but also rather strong back azimuthal variations of the splitting parameters that are globally consistent with the presence of two anisotropic layers corresponding to the lithosphere with a frozen fast orientation related to the paleospreading direction and to the underlying present-day asthenospheric mantle flow related to the plate drag [Fontaine et al., 2007].

\section{4. $P_{\text {pol }}$ and Earthquake Location by the Tsunami Warning System in Tahiti}

[37] Real-time automatic earthquake detection and location is achieved by the Centre de Prévention Polynésien des 

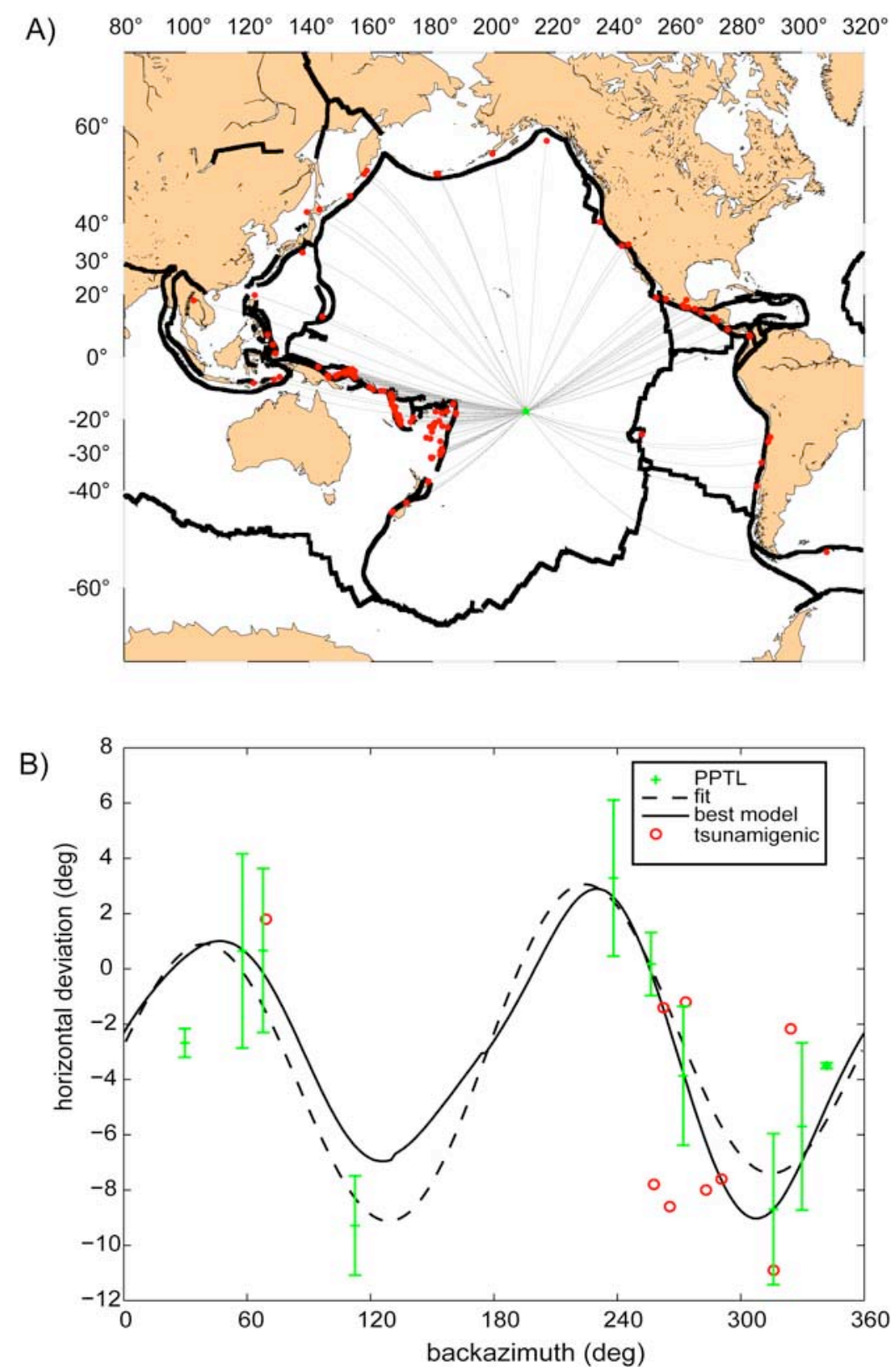

Figure 9. (a) Location of 130 events we used to measure $P_{\text {pol }}$ deviation at station PPTL. (b) Observed azimuthal polarization deviation versus great circle back azimuth for the seismic station PPTL in Tahiti. Error bars correspond to SMAD values. We compared the $P_{\mathrm{pol}}$ observations with the predicted values for our best model (black curve). This preferred model was obtained using the NA for two anisotropic layers in the upper mantle and a sensor misorientation. The dashed curve shows the fit with the harmonic analysis (equation (1)). Parameters of the fit with the harmonic analysis are listed in Table 1. The open circles represent the $P$ wave horizontal deviation of polarization observed for nine tsunamigenic earthquakes.

Tsunamis (CPPT, belonging to Commissariat à l'Energie Atomique/Laboratoire de Géophysique), the tsunami warning system of Tahiti, which uses a single station (PPTL) and the Tsunami Risk Evaluation through seismic Moment in Real time System (TREMORS) system [Reymond et al., 1991; Hyvernaud et al., 1993; Schindelé et al., 1995]. PPTL is part of the Comprehensive Nuclear Test Ban Treaty organization network and is recognized as a high-quality oceanic station, particularly by its low level of microseismic noise [Barruol et al., 2006]. To locate the seismic events, the detec- tion system combines the $P$ wave polarization direction and the time difference between $P$ and $S$ waves. The $P$ phase is filtered between 0.02 and $0.05 \mathrm{~Hz}$. The accuracy of the realtime event location is therefore strongly influenced by the $P_{\mathrm{pol}}$ that reflect the incoming azimuth of the ray, which is considered as the radial direction. A deviation of $5^{\circ}$ to $10^{\circ}$ of the $P_{\mathrm{pol}}$ from the theoretical, radial direction may induce a large error in the event location if the event occurs at teleseismic distance and therefore possible mislocations of several hundreds of kilometers on the epicenter. Furthermore, 

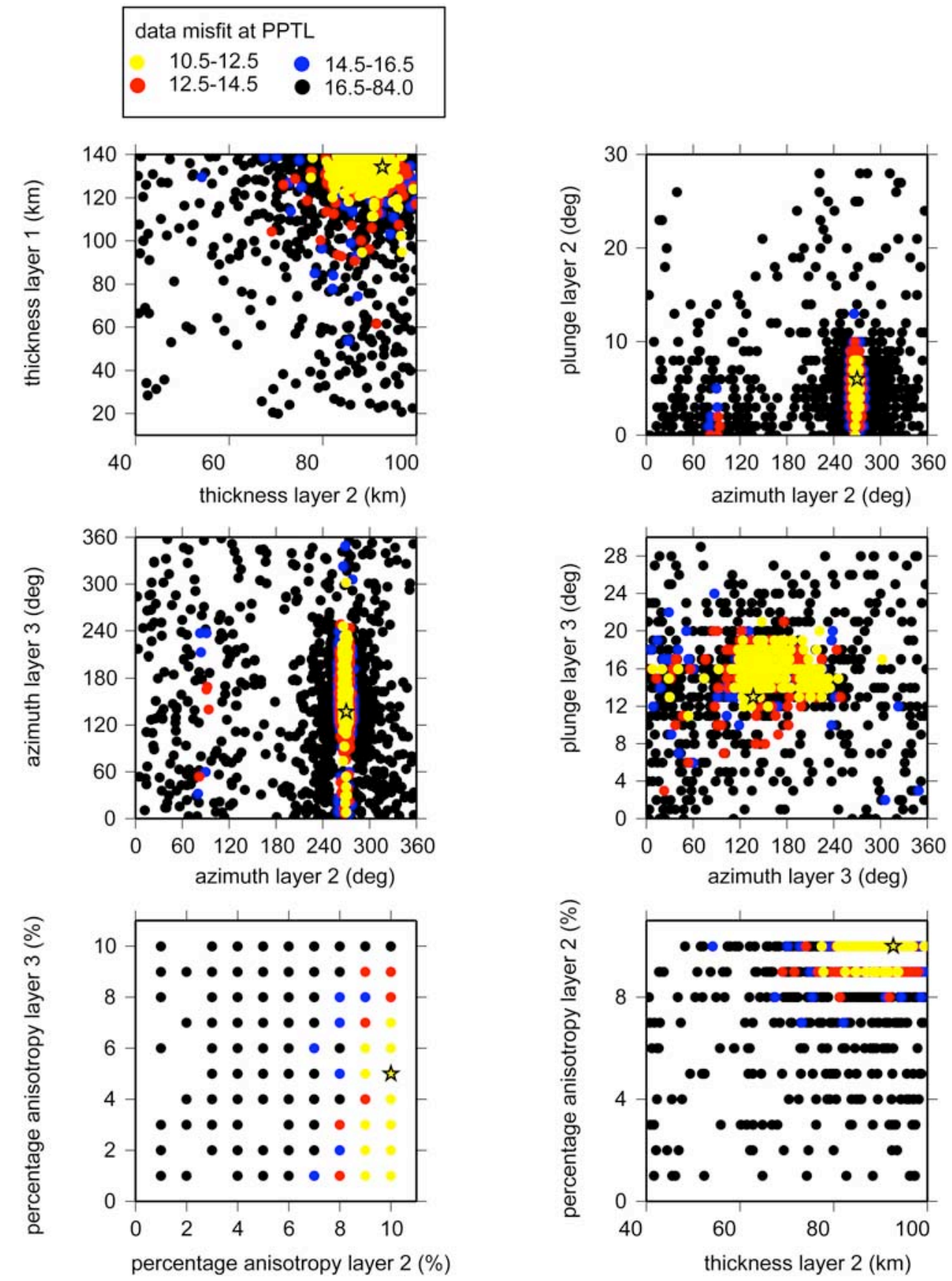

Figure 10. Results from the NA inversion at PPTL. We searched for two layers of anisotropy with four unknown parameters in each layer. Models produced by the NA algorithm, projected onto six pairs of axes. The circles are colored from black through blue then red to yellow, as the data misfit decreases. The star indicates the model found with best data fit.

the earthquake location obtained by TREMORS is also used to estimate the seismic moment in real time and TREMORS' warning is based on an estimate of the seismic moment. Our measurements of the actual horizontal $P$ wave polarization at station PPTL indicate differences up to $11^{\circ}$ relative to the theoretical radial direction (back azimuth) determined from the NEIC or ISC bulletins. We therefore propose to introduce a new parameter $\delta \theta_{\text {correction }}$ in order to improve the accuracy of the automatic location. This parameter is a correction which should be applied to the measured $P$ wave horizontal polarization direction $\theta_{\text {measured }}$ to obtain an estimate of the correct earthquake location. The parameter $\delta \theta_{\text {correction }}$ corresponds to the horizontal polarization deviation predicted by our best model at Tahiti which takes in account both seismic anisotropy and a sensor misorientation (black curve in Figure 9). This best model was obtained using the NA for two anisotropic layers in the upper mantle and a sensor misorientation. The correct back azimuth of the earthquake is determined by $\theta_{\text {apparent }}=\theta_{\text {measured }}-\delta \theta_{\text {correction. }}$. In Figure 9 we present examples of the application for nine tsunamigenic 
Table 3. Best Fitting Model Parameters Obtained From the Neighborhood Algorithm Inversion at TAU and PPTL ${ }^{\mathrm{a}}$

\begin{tabular}{|c|c|c|c|c|c|c|c|c|c|c|}
\hline$\underline{\text { Station }}$ & $\begin{array}{c}\text { Thickness } \\
(\mathrm{km})\end{array}$ & $\begin{array}{c}\rho \\
\left(\mathrm{g} / \mathrm{cm}^{3}\right) \\
\end{array}$ & $\begin{array}{l}\left\langle V_{P}\right\rangle \\
(\mathrm{km} / \mathrm{s})\end{array}$ & $\begin{array}{l}\left\langle V_{S}\right\rangle \\
(\mathrm{km} / \mathrm{s})\end{array}$ & $\begin{array}{c}\text { Anisotropy } \\
(\%)\end{array}$ & $\begin{array}{l}\text { Azimuth } \\
\text { (deg) }\end{array}$ & $\begin{array}{c}\mathrm{Pl} \\
(\mathrm{deg})\end{array}$ & $\begin{array}{l}\text { Strike } \\
(\text { deg })\end{array}$ & $\begin{array}{c}\text { Dip } \\
(\text { deg })\end{array}$ & $\begin{array}{l}\text { Misor } \\
(\mathrm{deg})\end{array}$ \\
\hline \multirow[t]{3}{*}{ TAU } & 32.0 & 2.8 & 6.34 & 3.66 & 0 & N/A & N/A & 0 & 0 & 1.79 \\
\hline & 205.5 & 3.5 & 8.03 & 4.36 & 10 & 168 & 29 & 0 & 0 & \\
\hline & N/A & 3.5 & 8.20 & 4.48 & 0 & N/A & N/A & 0 & 0 & \\
\hline \multirow[t]{4}{*}{ PPTL } & 11.0 & 2.7 & 5.84 & 3.37 & 0 & N/A & N/A & 0 & 0 & -3.13 \\
\hline & 92.8 & 3.5 & 8.03 & 4.36 & 10 & 270 & 6 & 0 & 0 & \\
\hline & 134.6 & 3.5 & 8.03 & 4.36 & 5 & 137 & 13 & 0 & 0 & \\
\hline & N/A & 3.5 & 8.20 & 4.48 & 0 & N/A & $\mathrm{N} / \mathrm{A}$ & 0 & 0 & \\
\hline
\end{tabular}

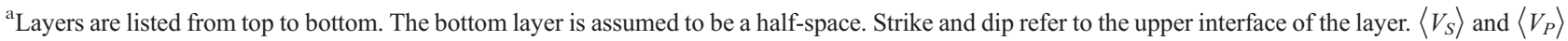
are average $S$ wave and $P$ wave velocities. Azimuth is the direction of the fast axis (in degrees). Pl is the plunge of the fast axis. The percentage anisotropy is similar for $P$ and $S$ wave; the remaining parameter $\eta$ is fixed at 1.03 [Farra et al., 1991; Frederiksen and Bostock, 2000]. Misor is the value of the sensor misorientation obtained from the harmonic analysis. We add Misor to the value of polarization deviation determined during the forward modeling of the neighborhood algorithm. N/A, not available.
\end{abstract}

earthquakes: two events considered during our $P_{\text {pol }}$ analysis occurring in Tonga regions on 6 October 1987 (data from Reymond et al. [1991]) and in the Kuril Islands on 15 November 2006, and seven events which were not considered in our $P_{\mathrm{pol}}$ analysis due to their epicentral distance exceeding $70^{\circ}$. The deviation of polarization for each of these events was reported by Schindelé et al. [1995]. The seven earthquakes occurred in Nicaragua on 2 September 1992; in

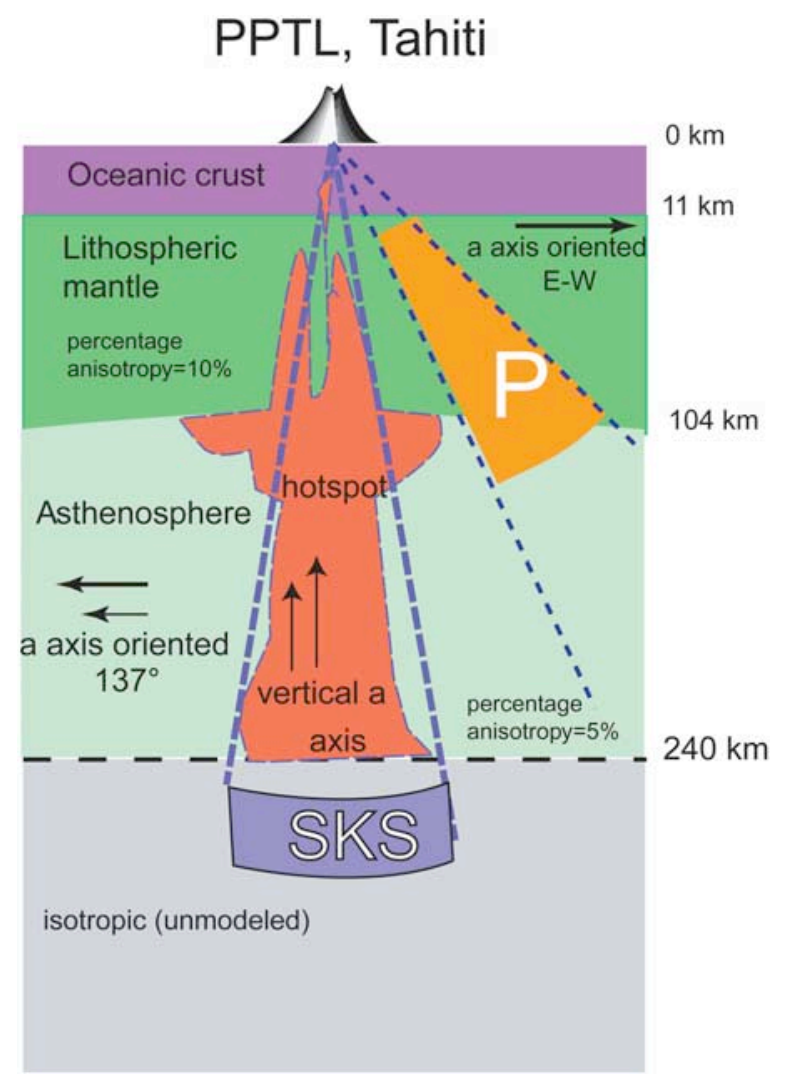

Figure 11. Cartoon illustrating the complementarity of $P_{\mathrm{pol}}$ and shear wave splitting measurements at Tahiti. $P$ waves and $S K S$ waves do not sample the same volume of upper mantle beneath the station. This may explain why $S K S$ seems to be isotropic at the Tahiti station (the $S K S$ waves likely travel through an upper mantle affected by the presence of the Society hot spot), whereas the $P$ waves are affected by a strong deviation, suggesting a clear upper mantle anisotropy.
Flores Sea, Indonesia, on 12 December 1992; in Hokkaido on 12 July 1993, in Guam on 8 August 1993; in Halmahera, Indonesia, on 21 January 1994; in Java, Indonesia, on 2 June 1994; and in Mindoro, Philippines, on 14 November 1994.

[38] We compared the horizontal polarization deviation obtained by the automatic location for these nine earthquakes (open circles in Figure 9) with the predicted horizontal deviation from our best model (black curve). Even if most of these earthquakes have an epicentral distance higher than $70^{\circ}$, we note a quite good agreement between the measured $P$ wave horizontal polarization direction $\theta_{\text {measured }}$ and the predicted horizontal deviation. This agreement is better if we consider the domain defined by the error bars. Therefore, we suggest the introduction in the automatic location process of a correction $\delta \theta_{\text {correction }}$ and an uncertainty on $\delta \theta_{\text {correction }}$ (i.e., SMAD values) to improve the real-time location of the earthquakes by TREMORS. Further work is necessary to determine the influence of velocity heterogeneities or dipping discontinuities on $P$ wave polarization at Tahiti. For the moment, all automatic detections by the TREMORS system are done without a station-dependent correction based on the effect of (1) station misorientation, (2) dipping seismic discontinuity, and (3) seismic anisotropy. If we apply such correction at each seismic station, we will be able to obtain a correct back azimuth of the epicenter and therefore to obtain a better location. Another example of application of this station-dependent correction is for receiver function studies for which we need to rotate the original $\mathrm{Z}, \mathrm{N}-\mathrm{S}, \mathrm{E}-\mathrm{W}$ components of the $P$ wave group into the ray coordinate system.

\section{Conclusions}

[39] In this paper, we analyzed $P$ wave polarization at Australian and Tahitian seismic stations. Since the $P_{\text {pol }}$ deviation may have various origins, we used an harmonic analysis to estimate the sensor misorientation and the amplitude of dipping effect compared to the amplitude due to anisotropic influence. Depending on the ratio of these two amplitude: $\delta \operatorname{dip}_{\max } / \delta \theta_{\max }$ we used either a grid search approach using Snell's law to model the effect of dipping structures or a NA inversion to characterize seismic anisotropy in the upper mantle.

[40] At CTAO and CAN, the dominating effect seems to be the presence of dipping structures, either at the Moho or within the crust. Beneath TAU, our results suggest that seismic anisotropy is the dominant effect on the deviation of 
$P$ wave polarization. At this station, seismic anisotropy is characterized by a $\mathrm{N}-\mathrm{S}$ fast anisotropic orientation in the upper mantle. This orientation is compatible with an upper mantle deformation induced by the fast northward motion of the plate.

[41] In Tahiti, the inversion of $P_{\text {pol }}$ measurements suggests the presence of two layers of anisotropy. The modeling favors the presence of a lithospheric and an asthenospheric layer, the former characterized by a fast axis oriented $\mathrm{E}-\mathrm{W}$ and the latter by a fast axis azimuth close to the NW-SE direction. This measurement is apparently in contradiction with the absence of detectable $S K S$ splitting at Tahiti but is, in fact, fully consistent with the other anisotropy measurements obtained in French Polynesia from $S K S$ splitting and surface wave tomography if one admits that the upper mantle structure beneath Tahiti is isotropic along the vertical direction. The origin of this apparent isotropy may be due to several causes: (1) a vertically oriented olivine $a$ axes, (2) the presence of melt, and (3) a mantle structure perturbed by the hot spot that render the medium isotropic.

[42] An important implication of the $P_{\mathrm{pol}}$ measurements concerns the real-time earthquake location that uses this polarization measurement to determine the back azimuth of an earthquake. We show that at Tahiti for $\delta \theta_{\max } \geq \delta \operatorname{dip}_{\max }$ this process may gain in accuracy by taking into account a correction of the $P$ wave polarization deviation due to both anisotropy and sensor misorientation.

[43] Acknowledgments. We thank N. M. Vitry, M. Sambridge, and D. Mainprice for fruitful discussions. We are grateful to the developers of the GMT software [Wessel and Smith, 1995]. We thank A. Frederiksen and M. Bostock for the code to compute synthetic seismograms and M. Sambridge for the NA code. The constructive comments of K. T. Walker, G. Leahy and the journal's Associate Editor have been appreciated. CAN is maintained by the Australian National University and GEOSCOPE, PPT is maintained by GEOSCOPE, PPTL by CEA, CTAO by IRIS/USGS, TAU by IRIS/IDA, and NWAO by IRIS/USGS. Polarization measurements from station PPTL were determined with PPOL tool, a utility program of Seismic Tool Kit (STK) project (http://sourceforge.net/projects/seismic-toolkit).

\section{References}

Barruol, G., and R. Hoffmann (1999), Seismic anisotropy beneath the Geoscope stations from SKS splitting, J. Geophys. Res., 104, 10,75710,774, doi:10.1029/1999JB900033.

Barruol, G., et al. (2002), PLUME investigates the South Pacific Superswell, Eos Trans. AGU, 83, 511, doi:10.1029/2002EO000354.

Barruol, G., D. Reymond, F. R. Fontaine, O. Hyvernaud, V. Maurer, and K. Maamaatuaiahutapu (2006), Characterizing swells in the southern Pacific from seismic and infrasonic noise analyses, Geophys. J. Int., 164, 516-542, doi:10.1111/j.1365-246X.2006.02871.x.

Bevington, P. R., and D. K. Robinson (1969), Data Reduction and Error Analysis for the Physical Sciences, 336 pp., McGraw-Hill, New York.

Bokelmann, G. H. R. (1995), P wave array polarization analysis and effective anisotropy of the brittle crust, Geophys. J. Int., 120, 145-162, doi:10.1111/j.1365-246X.1995.tb05917.x.

Bokelmann, G. H. R. (2002), Convection-driven motion of the North American craton: Evidence from $P$ wave anisotropy, Geophys. J. Int., 148(2), 278-287, doi:10.1046/j.1365-246X.2002.01614.x.

Brown, R. J. (1972), Lateral inhomogeneity in the crust and upper mantle from $P$ wave amplitudes, Pure Appl. Geophys., 101, 102-154, doi:10.1007/BF00876778.

Clitheroe, G. M., O. Gudmundsson, and B. L. N. Kennett (2000a), Sedimentary and upper crustal structure of Australia from receiver functions, Aust. J. Earth Sci., 47, 209-216, doi:10.1046/j.1440-0952.2000.00774.x.

Clitheroe, G. M., O. Gudmundsson, and B. L. N. Kennett (2000b), The crustal thickness of Australia, J. Geophys. Res., 105, 13,697-13,713, doi:10.1029/1999JB900317.

Collins, C. D. N. (1991), The nature of the crust-mantle boundary under Australia from seismic evidence, in The Australian Lithosphere, Spec. Publ., vol. 17, edited by J. B. Drummond, pp. 67-80, Geol. Soc. of Aust., Sydney.
Crampin, S., R. Stephen, and R. McGonigle (1982), The polarization of $P$ waves in anisotropic media, Geophys. J. R. Astron. Soc., 68, 477-485. Davis, P. M. (2003), Azimuthal variation in seismic anisotropy of the southern California uppermost mantle, J. Geophys. Res., 108(B1), 2052, doi:10.1029/2001JB000637.

Debayle, E., B. L. N. Kennett, and K. Priestley (2005), Global azimuthal seismic anisotropy: The unique plate-motion deformation of Australia, Nature, 433, 509-512, doi:10.1038/nature03247.

Farra, V., L. P. Vinnik, B. Romanowicz, G. L. Kosarev, and R. Kind (1991), Inversion of teleseismic $S$ particle motion for azimuthal anisotropy in the upper mantle: A feasibility study, Geophys. J. Int., 106, 421-431, doi:10.1111/j.1365-246X.1991.tb03905.x.

Finlayson, D. M., C. D. N. Collins, and D. Denham (1980), Crustal structure under the Lachlan Fold Belt, Southeastern Australia, Phys. Earth Planet. Inter., 21, 321-342, doi:10.1016/0031-9201(80)90136-3.

Fontaine, F. R., G. Barruol, A. Tommasi, and G. H. R. Bokelmann (2007), Upper mantle flow beneath French Polynesia from shear-wave splitting, Geophys. J. Int., 170, 1262-1288, doi:10.1111/j.1365-246X.2007.03475.x.

Frederiksen, A. W., and M. G. Bostock (2000), Modelling teleseismic waves in dipping anisotropic structures, Geophys. J. Int., 141, 401-412, doi:10.1046/j.1365-246x.2000.00090.x.

Girardin, N., and V. Farra (1998), Azimuthal anisotropy in the upper mantle from observations of $P$-to- $S$ converted phases: Application to southeast Australia, Geophys. J. Int., 133, 615-629, doi:10.1046/j.1365-246X. 1998.00525.x.

Gripp, A. E., and R. B. Gordon (2002), Young tracks of hotspots and current plate velocities, Geophys. J. Int., 150, 321-361, doi:10.1046/ j.1365-246X.2002.01627.x.

Heintz, M., and B. L. N. Kennett (2006), The apparently isotropic Australian upper mantle, Geophys. Res. Lett., 33, L15319, doi:10.1029/ 2006GL026401.

Hotelling, H. (1933), Analysis of a complex of statistical variables into principal components, J. Educ. Psychol., 24, 417-441, doi:10.1037/ h0071325.

Hyvernaud, O., D. Reymond, J. Talandier, and E. A. Okal (1993), Four years of automated measurement of seismic moments at Papeete using the mantle magnitude $M_{m}: 1987-1991$, Tectonophysics, 217, 175-193, doi:10.1016/0040-1951(93)90002-2.

Leahy, G. M., and J. Park (2005), Hunting for oceanic island Moho, Geophys. J. Int., 160, 1020-1026, doi:10.1111/j.1365-246X.2005.02562.x.

Maggi, A., E. Debayle, K. Priestley, and G. Barruol (2006), Azimuthal anisotropy of the Pacific region, Earth Planet. Sci. Lett., doi:10.1016/ j.eps1.2006.07.010.

Mainprice, D., G. Barruol, and W. Ben Ismail (2000), The seismic anisotropy of the Earth's mantle: From single crystal to polycrystal, in Earth's Deep Interior: Mineral Physics and Tomography from the Atomic to the Global Scale, Geophys. Monogr. Ser., vol. 117, edited by S. I. Karato, pp. 237-264, AGU, Washington, D. C.

Niazi, M. (1966), Corrections to apparent azimuths and travel-time gradients for a dipping Mohorovicic discontinuity, Bull. Seismol. Soc. Am., 56, $491-509$.

Nicolas, A., and N. I. Christensen (1987), Formation of anisotropy in upper mantle peridotites-A review, in Composition, Structure and Dynamics of the Lithosphere-Asthenosphere System, Geodyn. Ser., vol. 16, edited by K. Fuchs and C. Froidevaux, pp. 111-123, AGU, Washington, D. C.

Pearson, K. (1901), On lines and planes of closest fit to system of points in space, Philos. Mag., 2(11), 559-572.

Reymond, D., O. Hyvernaud, and J. Talandier (1991), Automatic detection, location and quantification of earthquakes: Application to tsunami warning, Pure Appl. Geophys., 135, 361-382, doi:10.1007/BF00879470.

Sambridge, M. S. (1999), Geophysical inversion with a neighbourhood algorithm. I. Searching a parameter space, Geophys. J. Int., 138, 479-494, doi:10.1046/j.1365-246X.1999.00876.x.

Schindelé, F., D. Reymond, E. Gaucher, and E. A. Okal (1995), Analysis and automatic processing in near-field of eight 1992-1994 tsunamigenic earthquakes: Improvements towards real-time tsunami warning, Pure Appl. Geophys., 144, 381-408, doi:10.1007/BF00874374.

Schulte-Pelkum, V., and D. K. Blackman (2003), A synthesis of seismic $P$ and $S$ anisotropy, Geophys. J. Int., 154, 166-178, doi:10.1046/j.1365246X.2003.01951.x.

Schulte-Pelkum, V., G. Masters, and P. M. Shearer (2001), Upper mantle anisotropy from long-period $P$ polarization, J. Geophys. Res., 106, $21,917-21,934$.

Shearer, P. (1999), Introduction to Seismology, 260 pp., Cambridge Univ. Press, Cambridge, U. K.

Shearer, P., and C. Chapman (1989), Ray tracing in azimuthally anisotropic media - I. results for models of aligned cracks in the upper crust, Geophys. J., 96, 51-64, doi:10.1111/j.1365-246X.1989.tb05250.x.

Shibutani, T., M. Sambridge, and B. L. N. Kennett (1996), Genetic algorithm inversion for receiver functions with application to crust and uppermost 
mantle structure beneath eastern Australia, Geophys. Res. Lett., 23, 1829-1832, doi:10.1029/96GL01671.

Silver, P. G., and W. W. Chan (1988), Implications for continental structure and evolution from seismic anisotropy, Nature, 335, 34-39, doi:10.1038/ $335034 \mathrm{a} 0$.

Silver, P. G., and W. W. Chan (1991), Shear wave splitting and subcontinental mantle deformation, J. Geophys. Res., 96, 16,429-16,454.

Thoraval, C., A. Tommasi, and M.-P. Doin (2006), Plume-lithosphere interaction beneath a fast moving plate, Geophys. Res. Lett., 33, L01301, doi:10.1029/2005GL024047.

Tommasi, A., M. Godard, G. Coromina, J. M. Dautria, and H. Barsczus (2004), Seismic anisotropy and compositionally induced velocity anomalies in the lithosphere above mantle plumes: A petrological and microstructural study of mantle xenoliths from French Polynesia, Earth Planet. Sci. Lett., 227, 539-556, doi:10.1016/j.epsl.2004.09.019.

Vinnik, L. P., G. L. Kosarev, and L. I. Makeyeva (1984), Anisotropiya litosfery po nablyudeniyam voln SKS and SKKS, Dokl. Akad. Nauk. USSR, 278, 1335-1339.

Vinnik, L. P., L. I. Makeyeva, A. Milev, and A. Y. Usenko (1992), Global patterns of azimuthal anisotropy and deformations in the continental mantle, Geophys. J. Int., 111, 433-437, doi:10.1111/j.1365-246X.1992. tb02102.x.
Voronoi, M. G. (1908), Nouvelles applications des paramètres continus à la théorie des formes quadratiques, J. Reine Angew. Math., 134, 198-287.

Webb, S. C. (1998), Broadband seismology and noise under the ocean, Rev. Geophys., 36, 105-142, doi:10.1029/97RG02287.

Wessel, R., and W. Smith (1995), New version of the generic mapping tools released, Eos Trans. AGU, 76, 329, doi:10.1029/95EO00198.

G. Barruol and G. H. R. Bokelmann, Laboratoire Géosciences Montpellier, Université Montpellier II, CNRS, F-34095 Montpellier CEDEX 5, France. (barruol@gm.univ-montp2.fr; bokelmann@gm.univ-montp2.fr)

F. R. Fontaine, Laboratoire GéoSciences Réunion, UR, IPGP, UMR 7154, 15 avenue René Cassin, BP 7151, F-97715 Saint Denis CEDEX 9 , Reunion Island, France. (fabrice.fontaine@univ-reunion.fr)

B. L. N. Kennett, Research School of Earth Sciences, Australian National University, Canberra, ACT 0200, Australia. (brian@rses.anu.edu.au)

D. Reymond, CEA/DASE/Laboratoire de Géophysique, Commissariat à l'Energie Atomique, BP 640 Papeete, Tahiti, 98713 French Polynesia. (reymond.d@labogeo.pf) 